BNWL -1069

UC- 80 , Reactor

Technology

\title{
SEALING MECHANISMS \\ FOR FFTF CLOSED LOOP AND \\ OPEN TEST POSITION CLOSURES
}

R. Kolowith

Engineering Department

FFTF Project

October 1969

The mechanisms evaluated in this report include commercial items that were not necessarily developed or manufactured to meet Government specifications, to withstand the tests to which they were subjected, or to operate as applied during this study.

BATTELLE MEMORIAL INSTITUTE

PACIFIC NORTHWEST LABORATORIES

RICHLAND, WASHINGTON 99352 
Printed in the United States of America Available from

Clearinghouse for Federal Scientific and Technical Information National Bureau of Standards, U.S. Department of Commerce Springfield, Virginia 22151

Price: Printed Copy $\$ 3.00$; Microfiche $\$ 0.65$ 


\section{$\underline{\text { ABSTRACT }}$}

A state-of-technology survey of existing static mechanical sealing mechanisms has been conducted to determine applicability to the Fast Flux Test Facility (FFTF) closed loops and open test position top face piping. Particular attention has been directed to the $1200^{\circ} \mathrm{F}$ liquid sodium environment, the remote make-and-break requirement, and the extremely compact space envelope typical of the closed loop reactor nozzle closure application. In the Fast Test Reactor (FTR) there are a variety of locations which must have seals capable of withstanding different but severe environmental conditions. Because of the high temperature sodium and radiation environments, only metal-to-metal seals were surveyed. The survey was also limited to devices that have had some association with liquid metal, high temperature gas, or remotely operable environments.

Brief descriptions of most of the mechanical sealing concepts that have been used and/or tested in some or all of the more critical environments common to FFTF are presented. From a literature search and a user and vendor survey, a list of candidate mechanical static sealing mechanisms has been recommended for a prototypical development program. 
TABLE OF CONTENTS

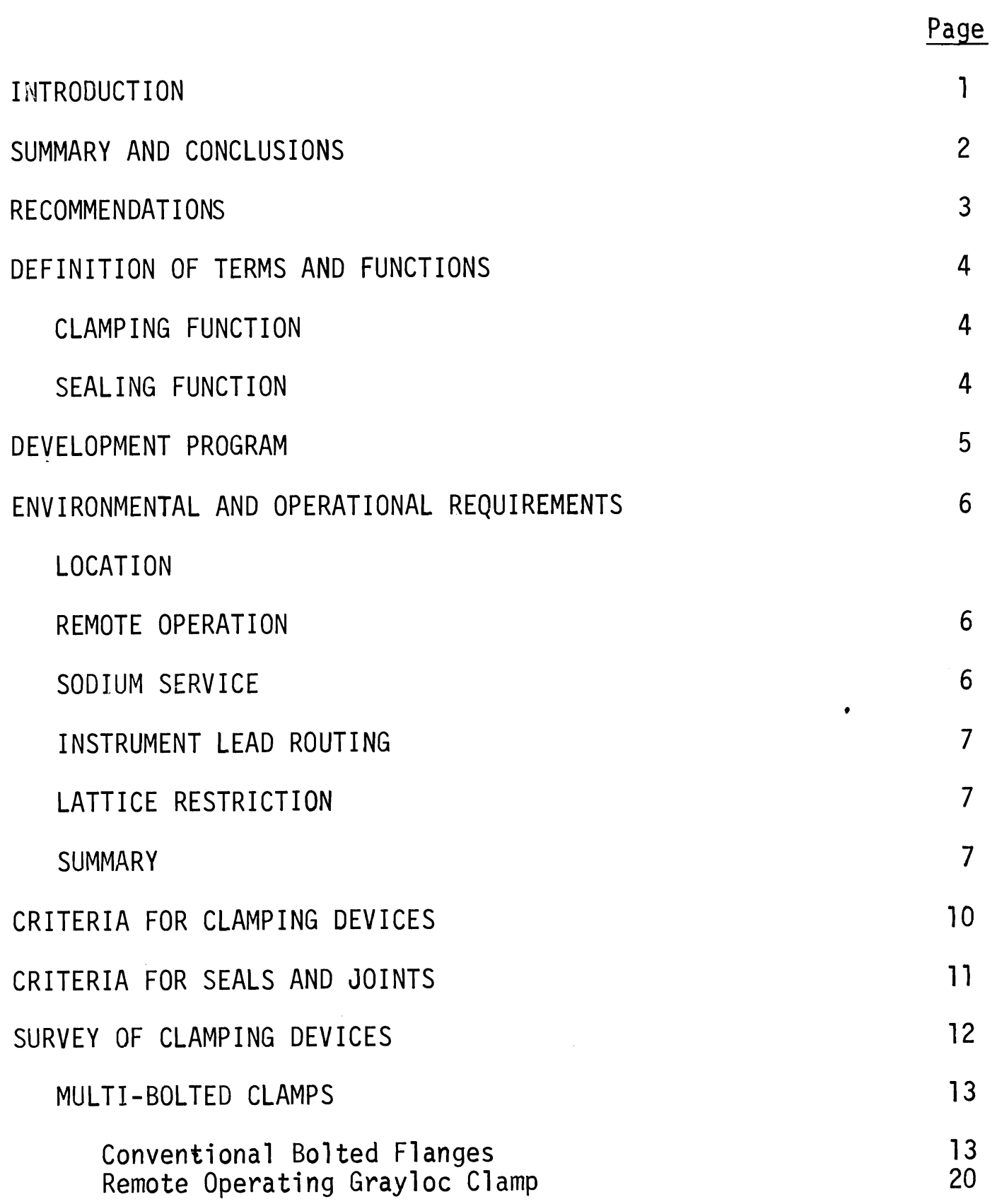


DUAL-BOLTED CLAMPS

Split-C Clamps

22

Dual-Bolted Flanges

SINGLE-BOLTED CLAMPS 28

Dome Seal Clamp $\quad 28$

Remote Operating Coupling $\quad 30$

Hanford Clamp 32

Quick Disconnect 34

DEVELOPMENT OF THE CREEP_COMPENSATING CONNECTOR 36

DESCRIPTION

RECOMMENDATION

SURVEY OF STATIC METAL SEALS AND JOINTS 39

$\begin{array}{ll}\text { HIGH LOAD SEALS } & 41\end{array}$

Four-Point Seal 41

Flat Metal Gasket $\quad 43$

Grayloc Seal 47

Lens Seal 51

Indented Seal 53

Metal 0-Ring $\quad 55$

LOW LOAD PRESSURE-ASSISTED SEALS 57

Hydrodyne Seal $\quad 57$

K-Seal 59

Hollow Metal 0-Ring 61

LOW LOAD NON-PRESSURE-ASSISTED SEALS 62

Conoseal

Freeze Seal

Fused Seal

Swedish Sealing Device $\quad 71$

REFERENCES R-1

BIBLIOGRAPHY B-1

APPENDIX A-1 


\section{LIST OF FIGURES}

Figure No.

Title

Page

Conventional Bolted Flange

15

2

Ring Joint Bolted Flange

16

3

Tongue and Groove Bolted Flange

17

4

Raised Face Bolted Flange

18

5

Loose Flanged Joint

19

6

Remote Operating Grayloc Clamp

21

7

Split-C Clamp

24

8

D.S.D. Temperature Compensating Coupling

25

9

Remote Operating Conoseal Clamp

27

10

Dome Seal

29

11

Remote Operating Coupling

Hanford Clamp

Quick Disconnect

Four-Point Seal

42

$15 a$

Flat Metal Gasket

44

$15 b$

Grooved Surface Flange

45

$15 \mathrm{c}$

Stepped Flange

46

16

Grayloc Seal and Clamp

48

17

Double Grayloc Seal Flange

49

18

Grayloc Dual Seal

50 


\section{LIST OF FIGURES (Continued)}

\begin{tabular}{|c|c|c|}
\hline Figure No. & Title & Page \\
\hline 19 & Lens and Grayloc Seals Double Flange & 52 \\
\hline 20 & Indented Seal & 54 \\
\hline 21 & Metal 0-Ring & 56 \\
\hline 22 & Hydrodyne Seal & 58 \\
\hline 23 & K-Seal & 60 \\
\hline 24 & Conoseal & 63 \\
\hline 25 & Double Conoseal Flange & 64 \\
\hline 26 & Freeze Seal & 67 \\
\hline 27 & Fused Seal & 69 \\
\hline 28 & Swedish Joint & 71 \\
\hline & APPENDIX A - LIST OF SKETCHES & \\
\hline Sketch No. & Title & Page \\
\hline SK-3-14540 & Reactor Arrangement for Concept V-A & $A-1$ \\
\hline SK-3-i 4567 & Reference Core Map & $A-2$ \\
\hline SK-3-12989 & Driver Fuel Internal Connector Assembly & $A-3$ \\
\hline$S K-3-14608$ & $\begin{array}{l}\text { Reactor Nozzle Connector, Internal Latching, } \\
\text { Creep Compensating }\end{array}$ & 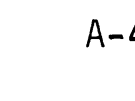 \\
\hline
\end{tabular}


SEALING MECHANISMS

FOR FFTF CLOSED LOOP AND

OPEN TEST POSITION CLOSURES

INTRODUCTION

One of the major problems in assuring individual removal and replacement of test specimens and hardware in the operation of the FFTF closed loop and open test positions is the selection of methods of sealing top face piping connections. The seal must perform effectively in a high radiation field at high temperatures to contain the flowing liquid sodium or the sodiumsaturated gas. The connection containing the seal must have the capability for remote make-and-break operations repetitively without failure. Two approaches are broadly applicable: the metallurgical joint (welded, brazed, or bonded) and the mechanical clamp-joint-seal combination.

The purpose of this report is to evaluate the state-of-technology of static mechanical sealing mechanisms, establish performance criteria, determine the need for development, and recommend candidate mechanisms for application to the FTR. Funding and technical direction of the development program wi11 be provided by Reactor Systems Task RS-E, Reactor Cover Hardware Development under schedule 189a No. 121RS. A parallel program under RS-C will be directed at developing reliable techniques and equipment for the remote welding and cutting of pipe and tubing containing liquid sodium or sodium vapors. This latter program will be reported in another document. The results of the two programs will be presented later and evaluated to provide a basis for selection of the detail design approach.

Prior to selection of the new reference core concept in December $1968^{(1)^{\star}}$, a driver duct seal and closure development program was initiated. It was based on the dispersed conical core configuration in which the driver ducts penetrated the reactor cover. Now that the requirement for a driver duct nozzle closure no longer exists, that program has been terminated. The scope of application of the mechanical sealing mechanisms selected in this report is limited primarily to the closed loop and open test position nozzles and the closed loop cross-arm piping. However, the features of these mechanisms will also be applicable to other penetrations in the reactor cover and to other piping disconnects.

* See list of references at the end of the text. 
The services of the Liquid Metal Information Center, operated for the USAEC by Atomics International, were used to assist in screening the enormous quantities of seal data that have been collected and to permit examining in more detail the reports of sealing methods that are potentially appplicable to the FTR. In addition to the iiterature search, a vendor survey was made, and the experience of previous Hanford projects and the results of recent FFTF studies were drawn upon in evaluating the state-oftechnology of candidate static mechical sealing mechanisms for adaptation to FTR $u=E$.

\section{SUMMARY AND CONCLUSIONS}

A state-of-technology survey was made, revealing that many different static mechanical sealing mechanisms have been tested and operated in envirorments somewhat similar to those that will exist in the FTR. However, either the tests were toc briei to assure long-torm reliability, or the operatin conditions were not rigorous enough to typify the anticipated FTR service. Consequentily, a develoment and testing program is considered necessary to establish the functional, metailurgical, and mechanical integrity of the sealing mechanisms for the proposed conditions of use.

None of the clamping devices in the sealing mechanism survey met all the design criteria. Many were unacceptabie because they required too much space, especially when made remotely operable. Further design refinements of the clamping devices may be recuired prior to development and testing. An FFTF conceptual design of a creep-compensating connector (or clamp) was initiated specifically to meet the design criteria and to avoid the drawbacks of the other c? amping devices surveyed.

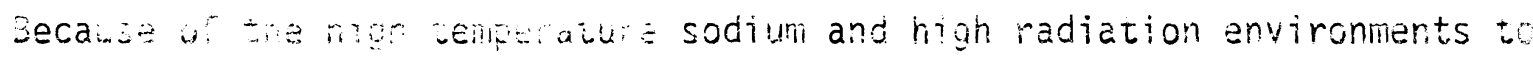
which the sealing mechanisms will be subjected, only metal-to-metal seals were surveyed. A number of the seals, all commercially available, appeared to meet most of the design criteria. It was concluded that these seals could be used in conjunction with modified joint configurations and redesigned clamping cevices for the devel rement and testing of candidate mecherica? sealing mechanisms for FT. Us. 


\section{RECOMMENDATIONS}

Since none of the clamps surveyed met all the design criteria, it is recommended that a prototype of the creep-compensating connector concept be designed and fabricated and subjected to a development testing program in conjunction with selected seals and joints. The creep-compensating connector has been conceived to overcome or avoid the major drawbacks encountered in the other types by providing such features as thermally compensated uniform seal loading, remote operability in a small space, accommodations for piping and instrument leads, and freedom from bolt thread problems.

It is further recommended that a backup clamping device be designed and fabricated as a prototype and subjected to a parallel test program. The Remote Operating Grayloc clamp is recommended for this purpose. Of all the working types surveyed, it appears to be the closest to the required state-of-technology. Possible problems of conflicting space envelope, temperature compensation, and thread galling and self-welding can undoubtedly be minimized by design modifications.

The following commercial seals are recommended to be tested in conjunction with the selected clamps using joint configurations and seal loads recommended by the seal manufacturers:

- Four-Point Sea?

- Flat Metal Gasket (annealed nickel with grooved joint faces)

- Grayloc Seal

- Hydrodyne Seal

- K-Seal

- Conoseal

These seals appear to be potentially adaptable to FTR use and are relatively free of the problems that were commonly encountered in the seal and joint survey -- problems such as self-welding between seal and joint, leakage at elevated and rapidly fluctuating temperatures, and leakage during high magnitude cyclic stresses. 


\section{DEFINITION OF TERMS AND FUNCTIONS}

The three main functioning parts of the static mechanical sealing mechanisms of this report are the clamp, joint, and seal. The seal prevents or limits the passage of particles, liquid, or gas across an intended barrier; the joint provides the mating surfaces to contain the seal; and the clamp provides the closure mechanism. The following terms as used in this report have distinct relationships to these functions:

- Electrical connector: a mechanical device to permit coupling and uncoupling electrical conductors.

- Top Face Nozzle: a projection or extension of the reactor vessel cover which has been designed to accept and seal the irradiation test specimens and hardware.

- Flange: a rib or rim of material to provide a surface for seal retention and clamping (as by bolting).

- Gasket: a specific type of seal with a flat rectangular cross section.

\section{CLAMPING FUNCTION}

The clamping function of the static mechanical sealing mechanism is accomplished by a) devices that apply an axial force directly to the mating surfaces of the joint, as the result of torquing an array of bolts or producing a differential displacement, or b) devices that use the principle of the wedge to obtain an axial force when an array of bolts is torqued. The conventional bolted flange, some quick disconnects, and the Hanford clamp are examples of the former. The Grayloc and Conoseal split-C clamps are examples of the latter.

\section{SEALING FUNCTION}

The sealing function of the static mechanical sealing mechanism (embodying metal-to-metal sealing) is accomplished by a) an elastic deformation seal, b) a plastic deformation seal, or c) a combination thereof. The elastic deformation seal is characterized by having no stresses that exceed the yield point of the material. The plastic deformation seal is characterized by a flow of the seal material. In a combination seal, the actual sealing surface undergoes localized flow while the balance of the material in the seal is elastically deformed. 


\section{DEVELOPMENT PROGRAM}

The objectives of the recommended development testing program are to:

- Provide experimental test data verifying the principle of operation of the recommended creep-compensating connector.

- Provide experimental test data verifying the principle of operation of the recommended backup clamping device.

- Provide experimental test data for each of the six seal concepts recommended for consideration.

- Establish a reference clamping design with effective seal and joint combinations.

- Develop a prototype mechanical sealing mechanism, with remote actuator, for statistical reliability testing.

- Establish a quality assurance program for design and fabrication of the component parts of the mechanical sealing mechanism. 
ENVIRONMENTAL AND OPERATIONAL REQUIREMENTS

\section{LOCATION}

Static sealing mechanisms will be required for pipe connections in the closed loop and open test position nozzles and the closed loop cross-arm piping. The following locations are anticipated:

- Closed loop nozzles (about 6 locations)

- Oper test position nozzles (about 3 locations)

- Closed loop cross-arm piping (about 6 locations)

\section{REMOTE OPERATION}

Because of the need to make and break some of these connections remotely, alignment characteristics inherent in a particular clamp or seal design will be of concern. Additionally, the remote connection must be capable of repetitive operation without failure. This repeatability requirement suggests that, for the mechanical sealing mechanisms discussed in this report, a remotely operated seat-facing device may be required, since it is almost a certainty that sodium deposits will be left on the sealing surfaces.

\section{SODIUM SERVICE}

A11 the sealing connections discussed are for liquid sodium or sodium vapor service. Sodium in liquid or vapor form at the FFTF design temperature w:11 remove most of the oxide-bearing surface layers, which otherwise provide corrosion resistance and lubrication in normal oxygen-containing environments. Sodium also is an apparent solvent for many materials, a property which can substantially change the character of alloys and compounds in contact with it. High operating temperatures of materials in sodium environments increase their apparent solubility by promoting mass transfer within materials with resultant property changes (2). These changes combine to cause diffusion welding, degradation of material properties, and microstructural failure at surfaces with consequent acceleration of wear $(3)$. The proposed material of fabrication is austenitic stainless steel (see Reference 4 for properties and applications). 
INSTRUMENT LEAD ROUTING

A supplementary requirement of the sealing mechanism for the top face nozzles is the need to transmit operational and test data from in-vessel sensors to readout devices external to the reactor. Approximately 36 electrical leads, four 1/4-inch flexible tubes, and one 1/2-inch flexible tube are expected to be routed through each nozzle past the seal barrier. The mechanical sealing mechanism at this junction will be required to accommodate some kind of an electrical connector (see drawing SK-3-14608)*. The impact on the design of the sealing mechanism is that the electrical connector will consume about 4-1/2 to 5 inches out of the I.D. of the clamping device and will occupy space in the center of the joint that some designs may not be able to tolerate.

\section{LATTICE RESTRICTION}

A requirement related to reactor core physics and the vertical array of the reference core concept creates the incentive to make the reactor core lattice as compact as possible (see Reference Core Map, SK-3-14567). Therefore, the space limitations on reactor nozzle seals and clamping devices will be restrictive. Any seal and clamping configuration that enables a reduction in the lattice dimension will be desirable.

SUMMARY

The specific environmental and operational requirements imposed on static mechanical sealing mechanisms for the closed loop and open test position nozzles and the closed loop cross-arm piping are summarized in Table I. They represent either the actual conditions expected, based on the conceptual design of the FTR, or a conservative envelope of possible ranges of conditions when conceptual data are lacking or inapplicable.

* See Appendix A for all drawings. 


\section{TABLE I}

Environmental and Operational Requirements of Static Mechanical Sealing Mechanisms

1. Allowable Sodium Leak Rate
a. Normal operation
0
b. Refueling operation

2. Allowable Cover Gas Leak Rate
a. Normal operation
$<10^{-7}$ atm $\mathrm{cc} / \mathrm{sec}$ helium from $500^{\circ} \mathrm{F}$ to $1200^{\circ} \mathrm{F}$ at $250 \mathrm{psia}$
b. Refueling operation
$<10^{-7} \mathrm{~atm} \mathrm{cc} / \mathrm{sec}$ helium from $400^{\circ} \mathrm{F}$ to $500^{\circ} \mathrm{F}$ at $50 \mathrm{psia}$

3. Temperature
a. Design
b. Normal operation
C. Refueling
d. Transient
Rate of change
e. Thermal cycles

$1200^{\circ} \mathrm{F}$

$500-1200^{\circ} \mathrm{F}$

$400-500^{\circ} \mathrm{F}$

$1400^{\circ} \mathrm{F}$

$30^{\circ} \mathrm{F} / \mathrm{sec}$

100 maximum

$400^{\circ} \mathrm{F}$ to $1200^{\circ} \mathrm{F}$ to $400^{\circ} \mathrm{F}$ in two hours

4. Pressure
a. Design
b. Normal operation
c. Refueling
d. Transient

$$
\text { Duration }
$$
e. Burst

250 psia

Atmospheric to 100 psi

Atmospheric to 50 psi

1000-10,000 psi

milliseconds

Undefined

5. Radiation Level
a. Neutrons (intermediate)
$10^{3} \mathrm{~N} / \mathrm{cm}^{2} / \mathrm{sec}$
b. Gamma
$\sim 10^{4} \mathrm{R} / \mathrm{hr}$ 
TABLE I (continued)

Environmental and Operational Requirements of Static ilechanical Sealing

6. Operational Mode

7. Frequency of Removal

8. Clamp Space Envelope
a. Height
b. Diameter

9. Seal Diameter

10. Reliability and Confidence Level

11. Seal Life

12. Contained Media

13. External Media

14. Primary Loop Flow
Remote

Minimum 20 times in 10 years

$$
\begin{aligned}
& 210 " \\
& \sim 71
\end{aligned}
$$

$6-7$

100 consecutive tests without a failure.

1.0 year

Sodium and/or inert gas

Air, nitrogen, or argon

0 to $600 \mathrm{gpm}$ 


\section{CRITERIA FOR CLAMPING DEVICES}

Minimum criteria for selection, conceptual design, and development testing of the clamping devices are as follows.

1. A minimum gasket load must be maintained at a 11 times by the clamping device to compensate for thermal effects (expansion and creep). The gasket load can fluctuate above this minimum and still be satisfactory.

2. The maximum gasket load shall be limited to a value that provides a reliable working margin below the force resulting from a Design Basis Accident (DBA). The clamp shall automatically vent upon extreme overpressure of a DBA so as to prevent formation of a secondary missile.

3. The gasket load must be distributed uniformly by the clamp. A nonuniform load will result in localized leakage paths across the seal.

4. The disassembly-reassembly envelope of the clamp must be compact to stay within the lattice dimensions.

5. The operating characteristics of the clamp must be readily adaptable to remote applications.

6. The contacting surfaces of the clamping device must not be subject to galling in the extremely high temperature environment anticipated in the FTR. 


\section{CRITERIA FOR SEALS AND JOINTS}

Minimum criteria for selection, conceptual design, and development testing of the seals and joints are as follows.

1. Plastic and elastic seal deformation shall be utilized to initiate and maintain a seal. This criterion is necessary to accommodate the thermal transients and dynamic mechanical loads predicted for the closure.

2. To minimize the possibility of plastic work from thermal cycling, the sealing lines of contact shall not be directly exposed to full flange clamping loads.

3. Internal pressure may be utilized to assist closure, but the closure must remain leak-tight under varying pressure conditions.

4. To minimize the possibility of having to reface the joint frequently, the seal material shall be softer than the joint material.

5. If possible, the sealing seat shall be isolated from the sodium.

6. The joint configuration shall promote easy cleaning and/or refacing, since most seals recommended for this type of service require close dimensional tolerances and clean surfaces.

7. Temperature-compensating seals which are designed to compensate for thermal expansion shall not be utilized to assist closure, since this type of seal can be applied to advantage only in relatively stable temperature environments which allow time for the temperature compensating mechanism to heat or cool.

8. The materials must be compatible with sodium to minimize the possibility of overall corrosion and selective leaching.

9. The materials must be compatible with high temperature to minimize the deterioration of physical properties.

10. The materials must be compatible with a radiation environment to minimize the deterioration of physical properties.

11. The mating surfaces of the seal and joint must have surface finishes and dimensional tolerances compatible with the leakage requirements. 


\section{SURVEY OF CLAMPING DEVICES}

There are many methods of clamping that can be applied to provide the axial force required to hold two mating surfaces together or actually join them. Mechanical and magnetic devices are examples of the former, and the metallurgical method (e.g., welding) is an example of the latter. This report is concerned with mechanical clamping devices. The literature search revealed no evidence of magnetic sealing designs applied to reactor closed loops. Metallurgical sealing for application to the FTR is being separately investigated on a parallel basis and will be reported in a later document.

None of the clamps evaluated in the literature or the vendor survey met all the criteria for FTR use, although some showed promise if modified. The Remote Operating Grayloc clamp was found to be particularly close to complying with the criteria and, with modifications, is recommended as a backup clamp concept for development testing. The prime concept recommended for development testing is an FFTF design concept of a creep-compensating connector initiated specifically to meet all the criteria for FTR use.

The advantages and disadvantages of the clamping devices surveyed, and their potential application to the FTR, are discussed as follows. For the purpose of this report, the various clamping devices have been grouped into three general categories: a) multi-bolted clamps, b) dual-bolted clamps, and c) single-bolted clamps. Within each category the mechanisms share a number of common characteristics.

The multi-bolted design approach was the first clamping solution to gain widespread use and acceptance. The dual-bolted (later four-bolted for Code acceptance) split-c clamps evolved as an improvement in reducing the size and operating time and in providing an even more uniform seal load distribution. Many of the single-bolted designs were derived as practical solutions to restricted space and remote operating applications. 


\section{MULTI-BOLTED CLAMPS}

Some of the more significant characteristics that the multi-bolted clamps have in common are as follows.

- The uniformity of the seal load at steady-state conditions is a function of the number of bolts used in the design and the rigidity of the bolt flanges.

- In general, the multi-bolted design requires more space than the other clamping concepts. The size of the assembly is a function of operating conditions such as internal pressure, loads, moments and torque.

- In general, operating time is extended and adaptability to remote operating applications is restrictive.

Conventional Bolted Flanges

\section{-Description-}

The conventional bolted flange, shown in Figure 1, obtains the axial force required to initiate a seal by torquing some configuration of bolts to a given value.

There have been a number of flange variations operated and tested in high temperature sodium environments. One that has been tested in sodium to $1100^{\circ} \mathrm{F}$ and $50 \mathrm{psig}$ is the ring-joint flange, shown in Figure 2. These flanges were welded to $0.5-i n$. IPS pipe and performed satisfactorily for 4,400 hours in a small thermal test loop. However, the testing was limited to occasional thermal cycling from $500^{\circ} \mathrm{F}$ to $1100^{\circ} \mathrm{F}^{5}$.

Another flange variation is the tongue-and-groove flange, shown in Figure 3. Gaskets, when used in the assembly, were made of $20 \mathrm{mi} 1$ thick tantalum sheet: The configuration leaked when subjected to $1100^{\circ} \mathrm{F}$ sodium at 50 psig. The tongue-and-groove concept was then modified. The faces of such modified flanges have either one or two tapered raised rings, 1/8 in. thick at the base and 1/32 in. thick at the bearing surface, which fit together to deform a $20 \mathrm{mi} 1$ thick iron gasket ${ }^{5}$. This concept performed satisfactorily when tested with $1300^{\circ} \mathrm{F}$ sodium at 50 psig. 
A raised-face fiange, shown in Figure 4 , was also tested in $1100^{\circ} \mathrm{F}$ sodium. The flanges were machined with raised bearing surfaces $3 / 16$ in. wide on both flanges. The bearing surfaces were then machined with concentric grooves. The gaskets used with this configuration were $20 \mathrm{mil}$ thick tantalum sheet. Leakage occurred after a few hundred hours when gasket material subject to atmospheric oxidation was used during the test.

The British have had some success with concentrically grooved faces on the mating flanges. The concentrically grooved design for sodium service, shown in Figure 5, utilized an annealed nickel gasket to form a ieakfree seal using carbon dioxide at $600^{\circ} \mathrm{C}$ and $500 \mathrm{psig}^{8}$. The largest diameter joint tested to these conditions was two inches. The joint employs loose flanges. The advantages of this are a lower rate of heat transfer to the bolts and improved performance in cyclic stress environments.

\section{-Evaluation-}

Published information shows that the use of bolted flanges has been limited and not particularly successful when placed in liquid metal service. One of the difficulties in trying to complete a closure with this clamping mechanism is the requirement that a uniform load distribution must be applied to the seal. To achieve this loading, great care must be taken in applying the proper torquing sequence. Another difficulty of this design is the bolt deterioration that results from high and/or cyclic sodium operating temperatures. Common types of bolt deterioration experienced under high temperature service conditions are elongation (bolt creep), thread galling, and fusion.

\section{-Recommendation-}

There are two other inherent disadvantages that appear to disqualify this mechanism for FTR use. One is the large diameter flanges that are required to assure adequate strength. The other is the bolt deterioration that can be expected to result from the high operating temperatures. Therefore, the bolted flange, with any of its joint or flange variations, is not recommended as a clamping candidate for the FTR static mechanical sealing mechanisms for the closed loops and open test positions of the FTR. 

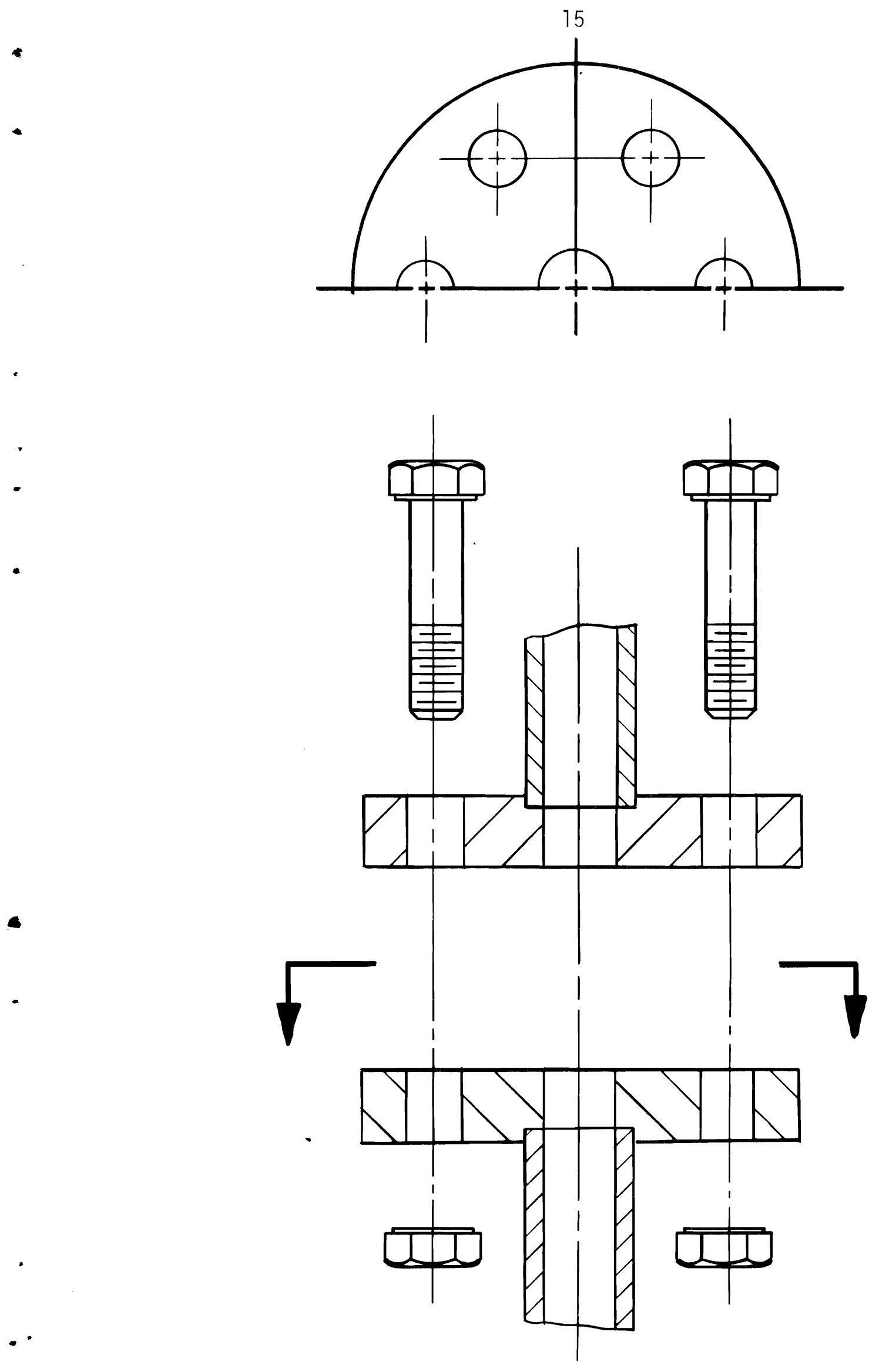

Figure $\mathbf{I}$ - Conventional Bolted Flange 

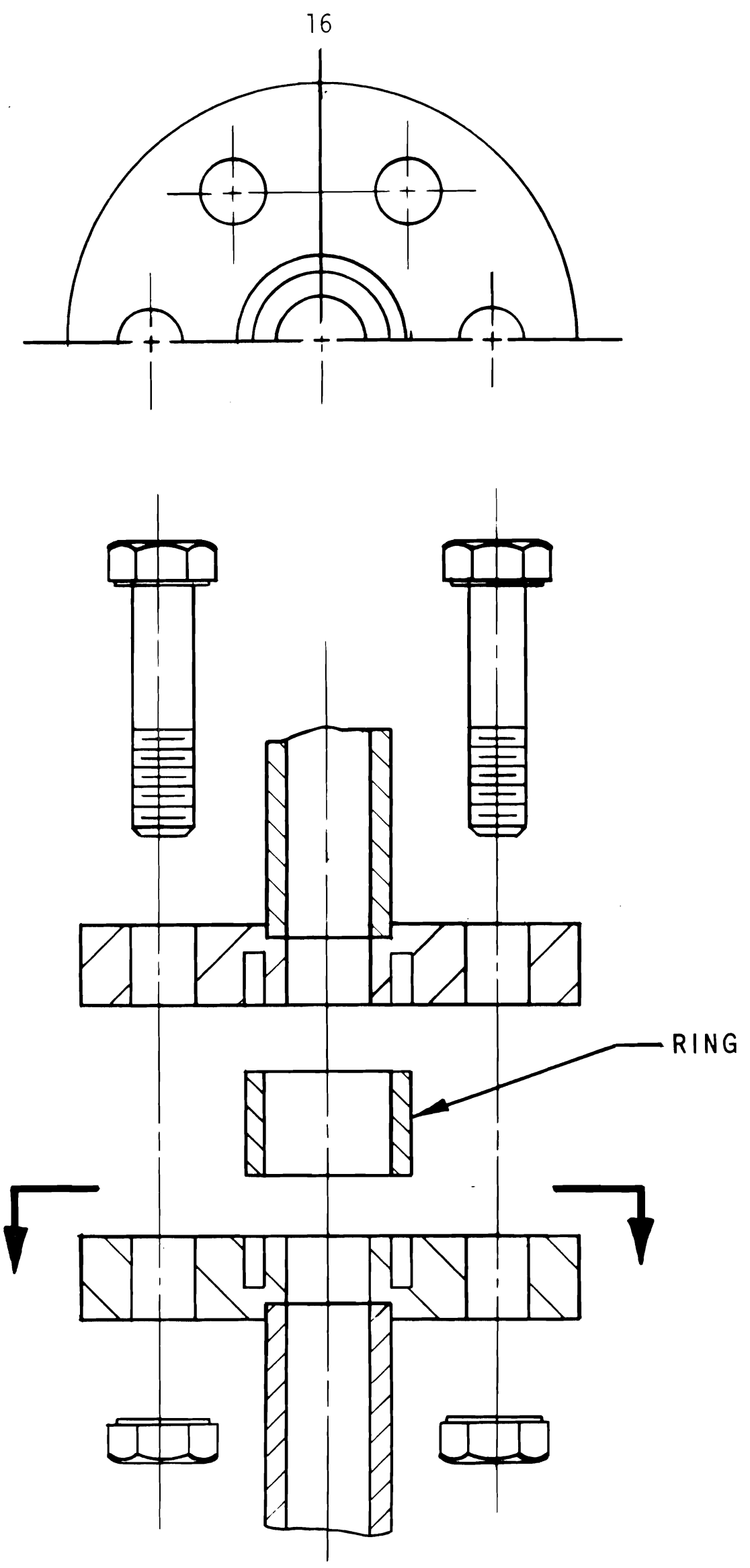

Figure 2. Ring Joint Bolted Flange 
$*$
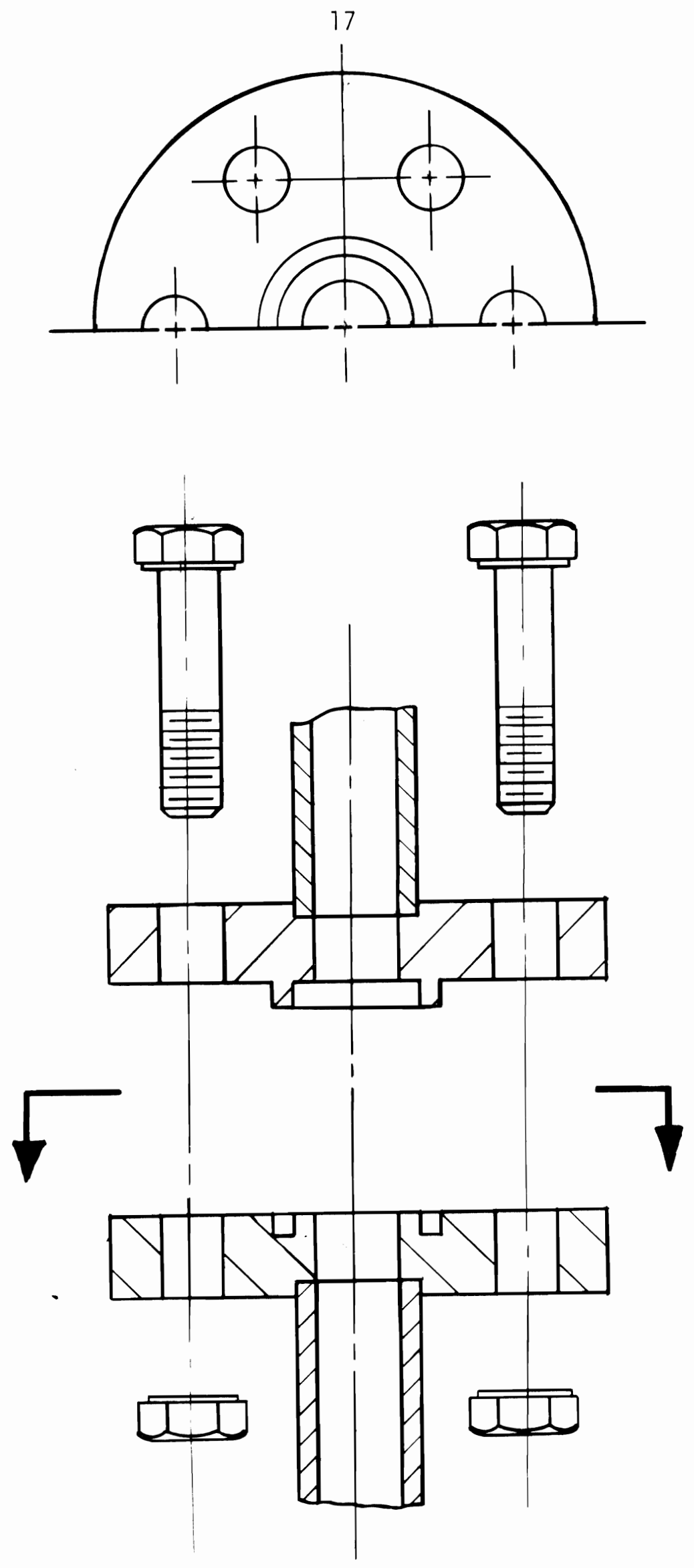

Figure 3. Tongue And Groove Bolted Flange 

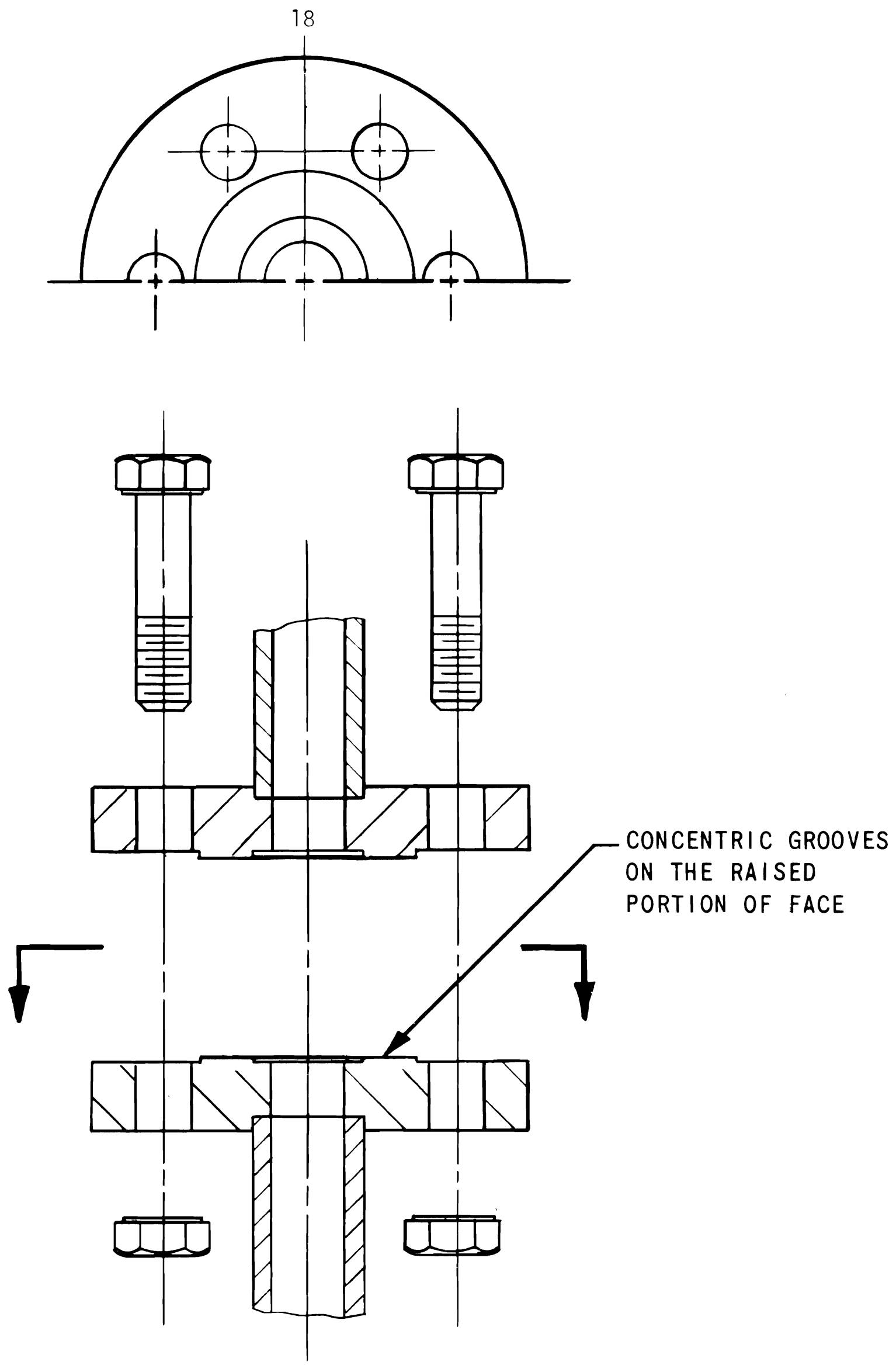

Figure 4. Raised Face Bolted Flange 


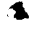

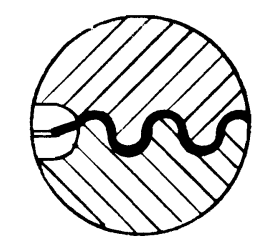

DETAIL A

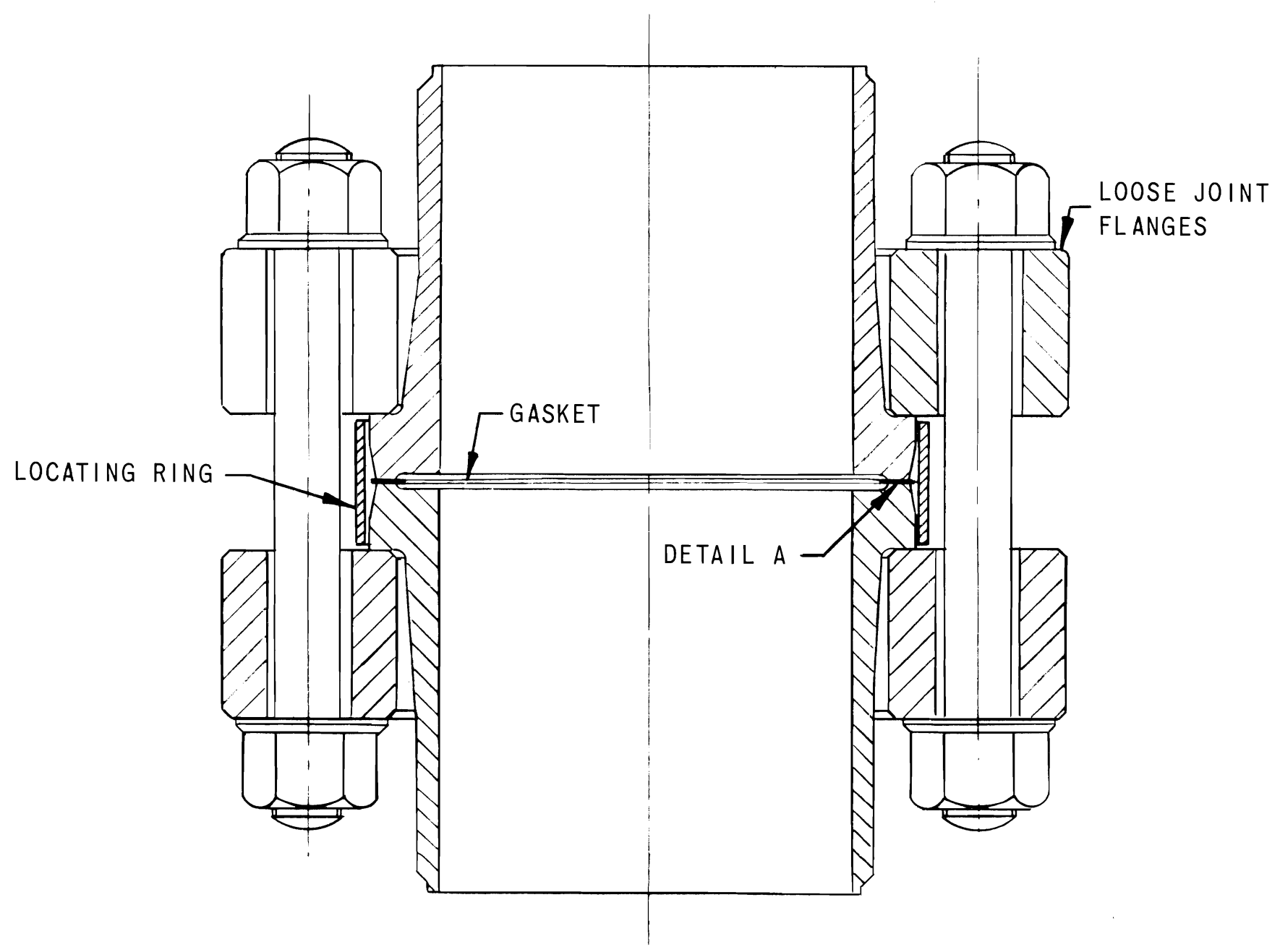

FIGURE 5. Loose Flanged Joint 
Remote Operating Grayloc Clamp

\section{-Description-}

A Remote Operating Grayloc clamping device design, shown in Figure 6 , has been proposed by Gray Tool Company specifically for FFTF. The clamping device is a combination of a threaded and a bolted joint. The seal loading bolts are all retained in the central plug which is postioned by rotation. The number of degrees of plug rotation is small, functioning in a manner similar to that of the standard breech-lock mechanism. Then the caotive boits are tightened in sequence to transmit load to the seal.

\section{-Evaluation-}

The device as shown has not been proven and retains many of the disadvantages of the bolted flange. The bolted seal loading configuration retains the inherent inability to assure a uniform seal load. The common types of bolt deterioration that may be experienced under high-temperature service conditions are bolt creep, thread aling. ancifusion. However, there are several advantages of this design that rave it attractive for FTR use. One advantage is the relatively small area cccupied by the clamping device while incorporating state-of-technology design features. Another advantage is the captive bolt feature and the breech-lock type thread on the centrai plug that will facilitate remote operation. still another advantage of the design is the feature of a large number of evenly distributed seal loading positions.

$$
\text { -Recommondzt: zr- }
$$

It is recommended that the design of the Remote Operating Grayloc clamp be modified as follows to compensate for the apparent disadvantages and that a prototype be fabricated and tested as a backup ciamping device for the FTR static sealing mechanisms for the closed loops and open test positions.

- Use Belleville springs under the head of each seal loading bolt.

- Use the bolt head design that has been developed specifically for the remotely operated impact wrench.

- Use a tapered bresch-lock thread design to facilitate alignment during remote operation.

- Optimize the boit and plug thread desians to minimize galling. 

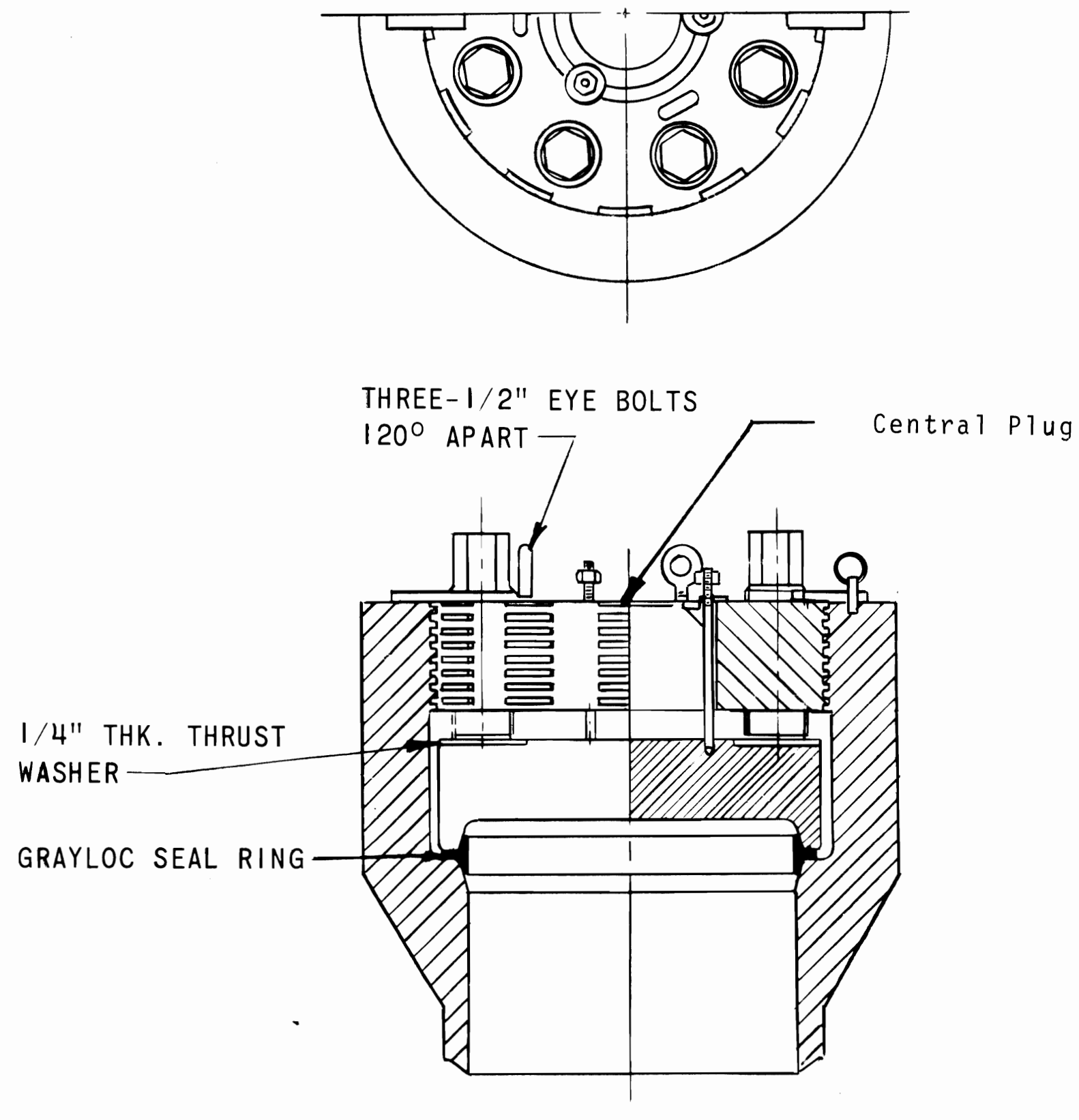

FIGURE 6. Remote Operating Grayloc Clamp 
DUAL-BOLTED CLAMPS

The dual-bolted clamps have been divided into two general categories: the split-c clamps and the dual-bolted flanges.

The split-c group is characterized by having the centerline of the bolt oriented perpendicular to the canterline of the mating piping. Several of the vendors have marketed a four-bolt version of the split-c design to comply with the piping code.

The dual-bolted flanges are characterized by having the centerline of the bolts oriented parallel to the centerline of the mating piping.

Split-C Clamps

\section{-Description-}

The split-C clamp design, shown in Figure 7 , is a segmented ring type of clamp design that has been used in sodium piping service ${ }^{6,7}$. There are variations of the spitit-C, or two segment ring clamp design, manufactured by several companies. Examples of the different clamps using a two-bolt design are the Autoclave Clamp, the Conoseal Clamp, and the Grayloc Clamp. Aeroquip/:iarmon and Gray Tool Company have both marketed a four-bolt split-C clamp design. The Marmon version is called "Conomaster."

The split-c clamp design obtains the required axial force on the seal from the wedging action that occurs when the two ring segments are drawn together.

Another variation of the split-C clamp design is the temperaturecompensating coupling, shown in Figure 8 (a product of D.S.D. Manufacturing Company). The device, as designed at the time of test, did not perform satisfactorily when subjected to a high temperature, cy'clic, liquid sodium environment ${ }^{6}$.

The flanges and seal are of conventional design. The Incone $x$ hinged band utilizes bimetallic retainer springs placed opposite each other to exert a greater axial force on the flanges. The springs are designed so that low temperature does not decrease the axial force. This is achieved by allowing the free end of the springs to rest in a depression in the band to prevent coiling. 
-Evaluation-

The split-C clamp design is probably the most widely used and most successful device for sodium piping service. The major disadvantage of this clamping concept for FTR top face closure is the additional space required to make and break the connection. The space required for the clamping device itself is actually smaller than that of the standard bolted flange, but the required envelope for operating the clamp has a much greater diameter. Also, the wedging clamp principle is conducive to galling and leakage during rapid thermal cycling. A major advantage of the Grayloc clamping concept over the bolted flange is tile ease with which a uniform load distribution can be applied across a seal.

The main disadvantages of the temperature-compensating coupling device for FTR use are its inability to apply large axial forces and its requirement for large diameters when applied to remote operation. Also, it did not perform well in high bending or torsional stress environments.

\section{-Recommendation-}

Because of the large operating space envelope required, the solit- $C$ clamp design is not recommended for use in the FTR top face open test position and closed loop static mechanical sealing mechanism. However, where room permits, it is recommended that this design be given serious consideration for other FFTF application. 


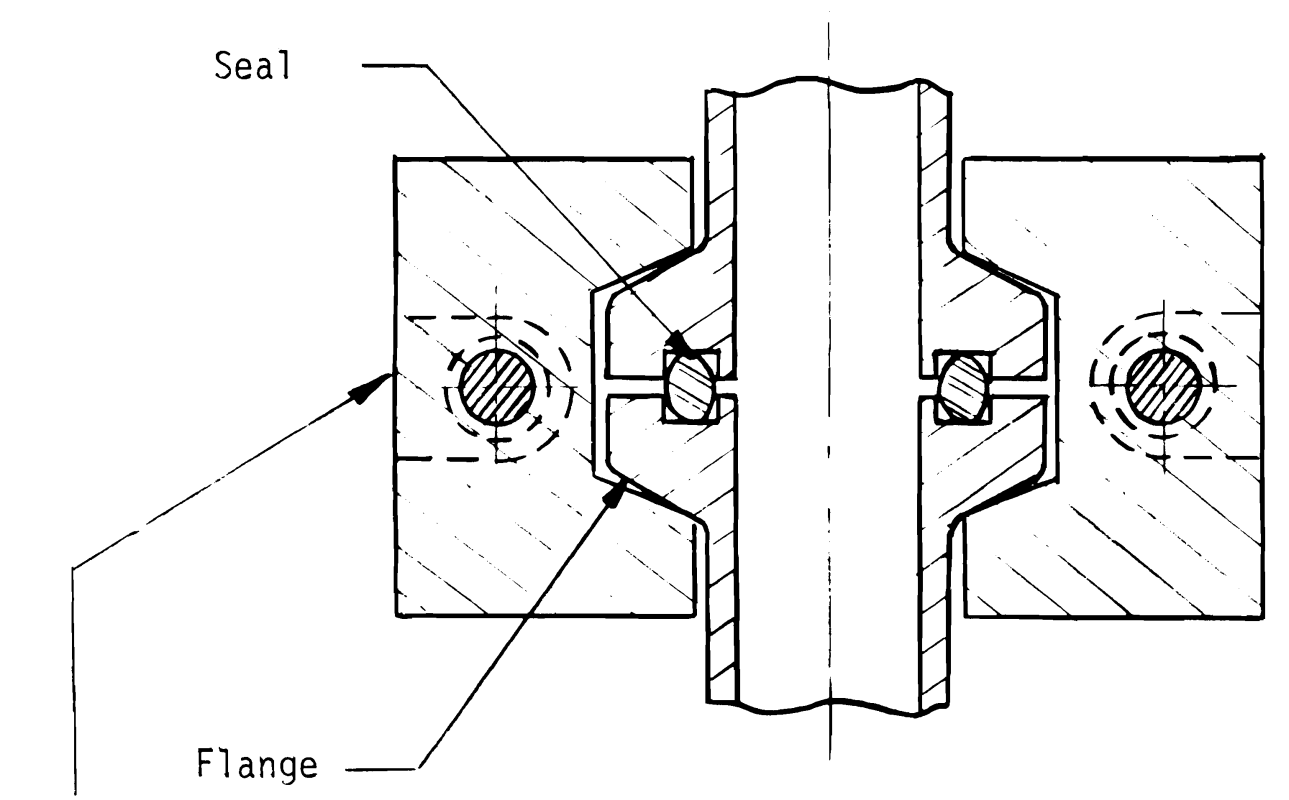

Clamp

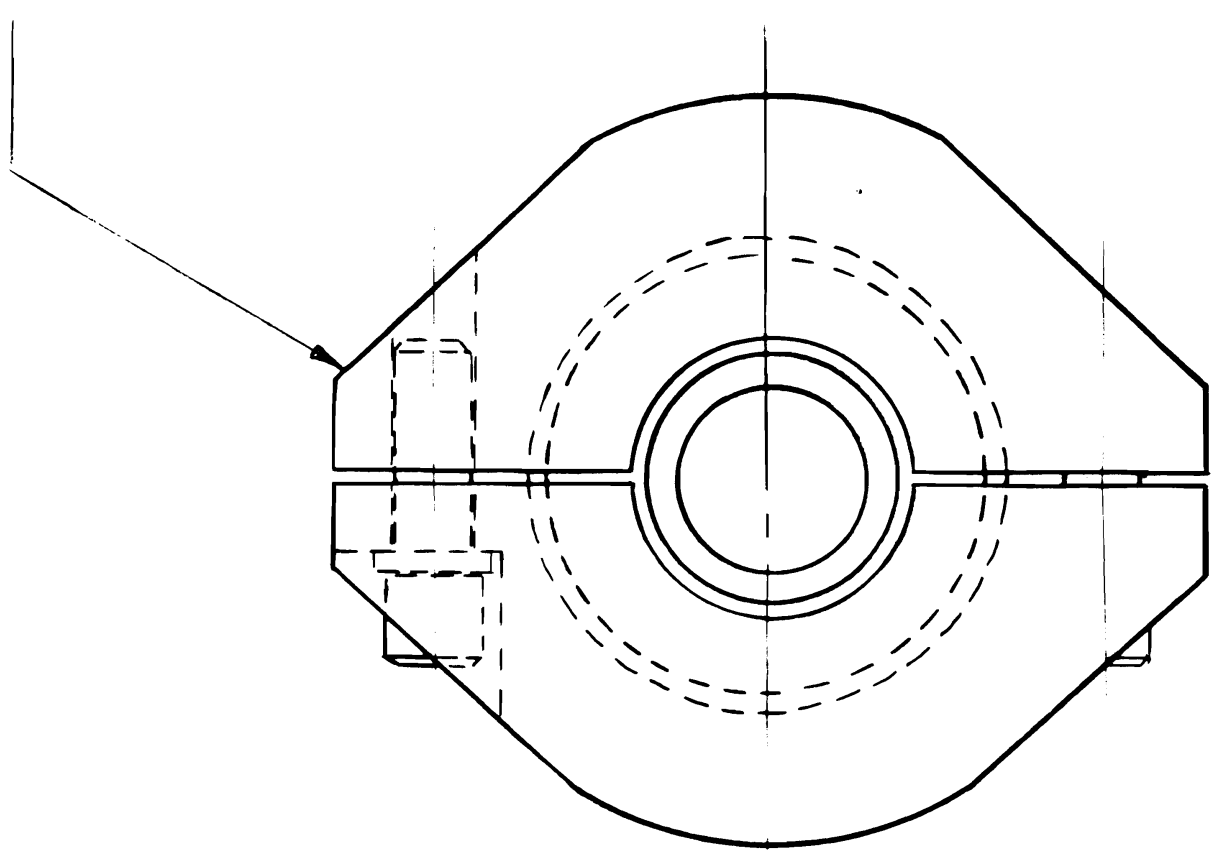

Figure 7 - Split-C Clamp 


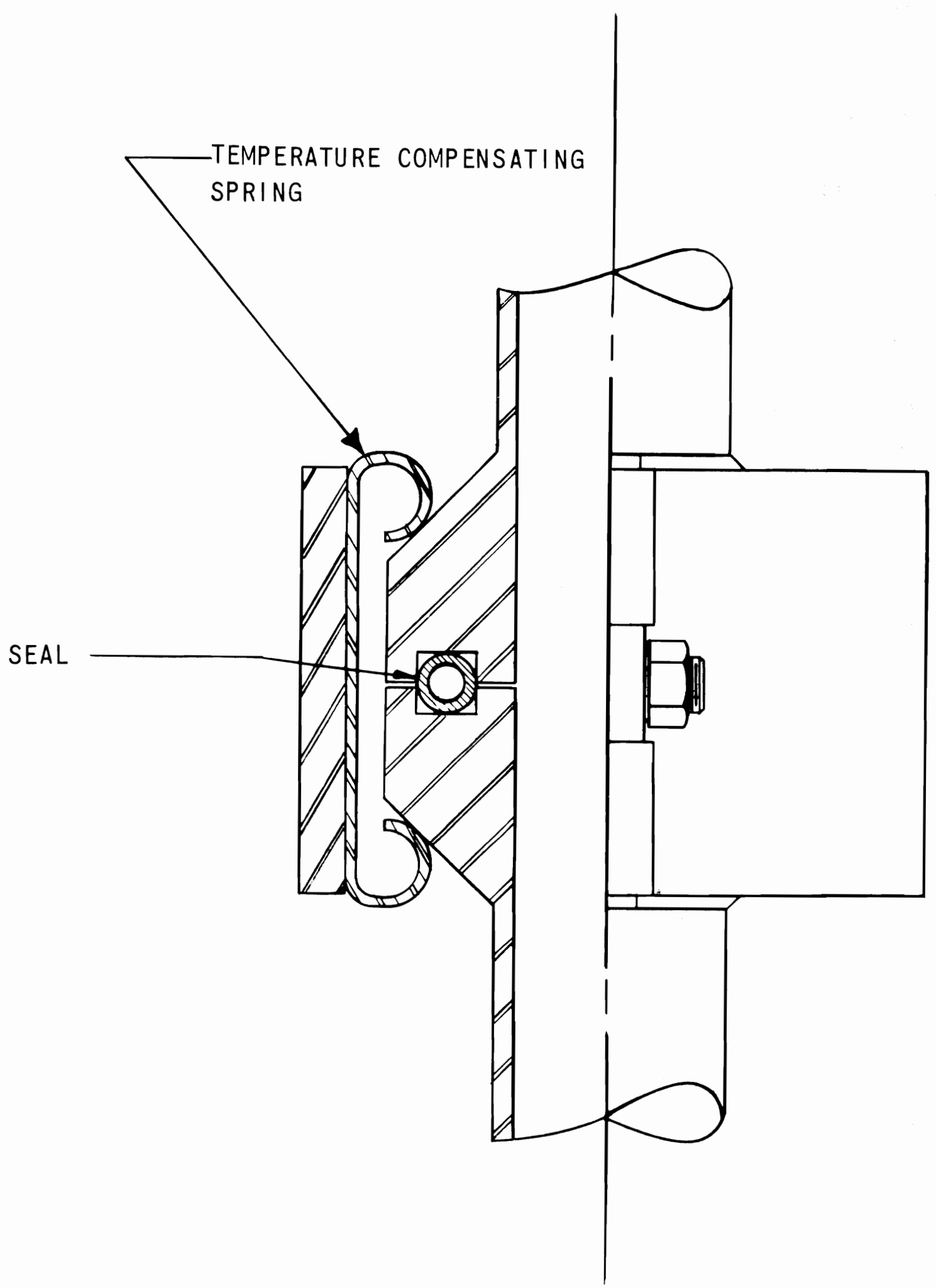

FIGURE 8. D.S.D. Temperature Compensating Coupling 
Dual-Bolted Flanges

\section{-Description-}

A remote operating Conoseal clamping device, shown in Figure 9, has been designed specifically for liquid sodium service. The design is a dualbolted variation of the conventional bolted flange. The joint uses a cap screw with a special head design instead of the standard nut and bolt design.

-Evaluation-

This design has been successful in remote operation in liquid sodium service. However, most of the design features of the standard bolted flange are retained. One additional problem that results from designing for the remote operation is that the load is only applied to two places around the flange. This can result in irregular seal loading.

\section{-Recommendation-}

Because of the large diameter and non-uniform seal loading inherent in this clamping design, it is not recommended for use in the FTR top face open test bosition and closed loop static mechanical sealing mechanism. 


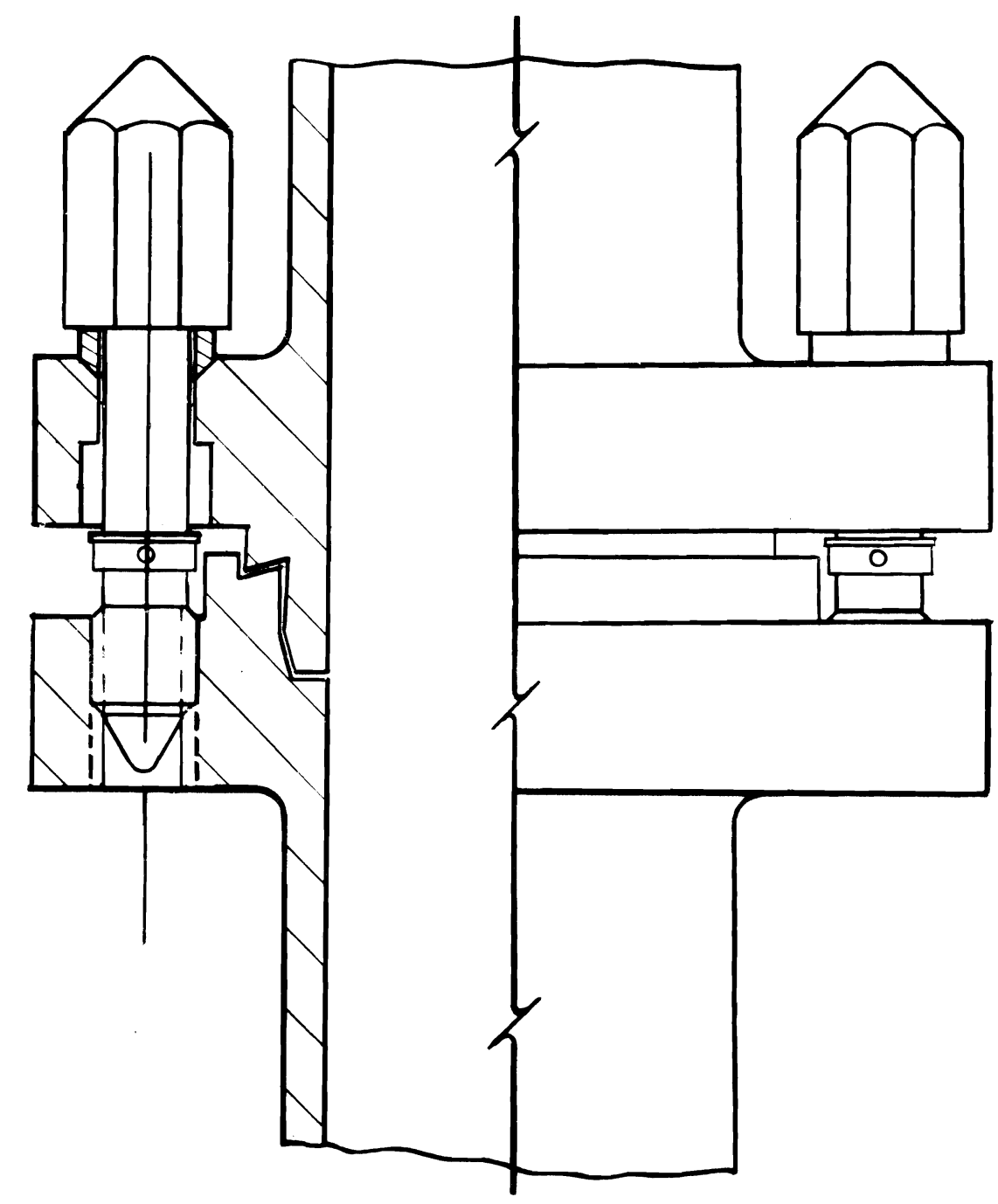

FIGURE 9. Remote Operating Conoseal Clamp 


\section{SINGLE-BOLTED CLAMPS}

The single-bolted clamps all have a common origin. They were designed for very specific applications and are not intended to have widespread applicability. However, most of the single-bolted clamps that were surveyed were very successful in their intended applications.

Dome Seal Clamp

\section{-Description-}

A dome seal closure mechanism, shown in Figure 10, was designed and tested specifically for high-teilperature, high-pressure reactor nozzle closure applications ${ }^{8}$.

The closure mechanism is basically a dome on a stem and is retained in such a manner as to be self-tightening under pressure. The dome edge pushes the seal ring and makes a metal-to-metal seal between the dome lip and nozzle by local yielding of the ring.

\section{-Evaluation-}

The dome seal mechanism has been used in a reactor gas loop with service conditions of $1500^{\circ} \mathrm{F}$ and 500 psig, with results indicating that the dome seal is a promising closure for pressure tube reactor application.

For the FTR top face open test position and closed loop applications, the design has several disadvantages. The internal operating mechanism, although compact in size, leaves little room for the routing of instrumentation leads and piping. The high disassembly torques associated with this design could be prohibitive.

\section{-Recommendation-}

Because of the dome seal mechanism's apparent incompatibility with instrumentation lead routing, this device is not recommended for use in the FTR top face open test position and closed loop static mechanical sealing mechanism. 


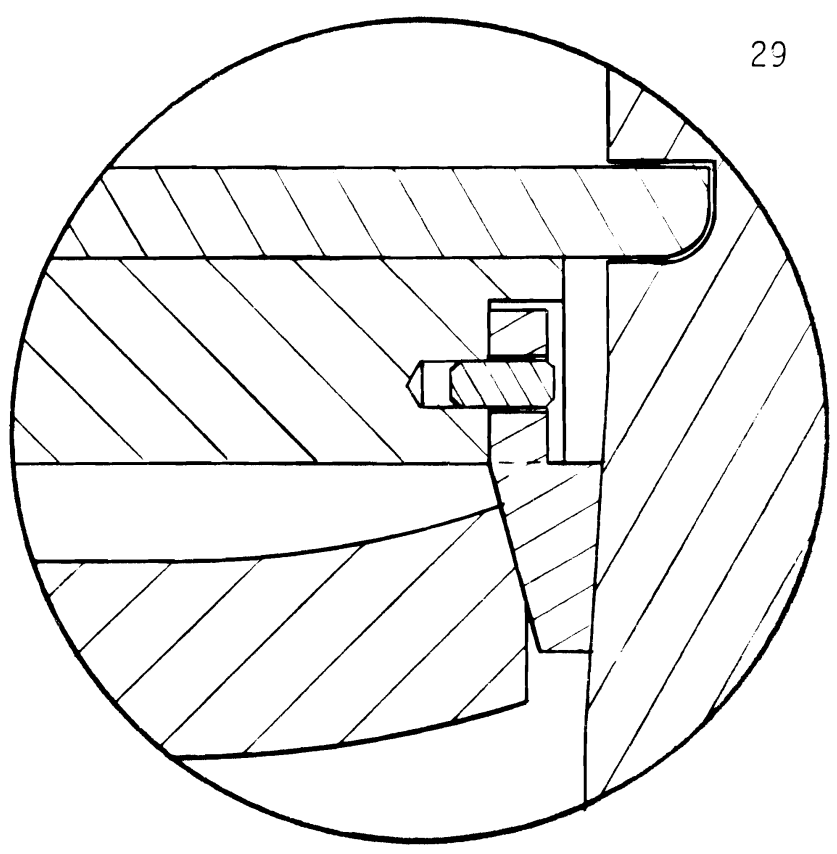

DETAIL A

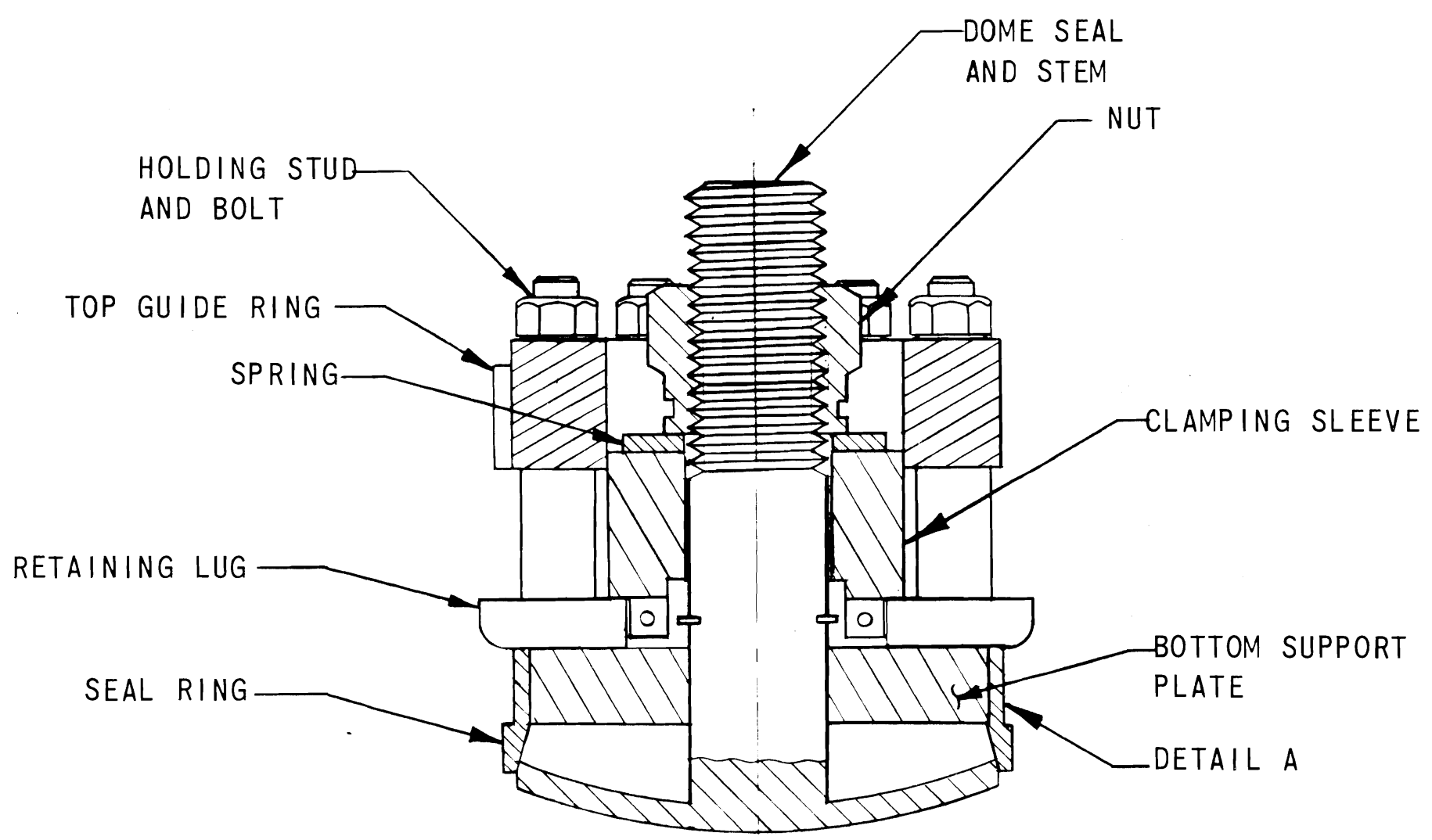

FIGURE 10. Dome Sea1 


\section{Remote Operating Coupling}

\section{-Description-}

A remote operating coupling, shown in Figure 11, was designed to connect 4-inch nominal pipe sizes or larger. A report of invention was prepared by General Electric on August 1, 1952. However, it was discovered that an item somewhat similar but not intended for remote application is manufactured by the Thornhi11-Craver Company, Houston, Texas, under the trade name of "Unibolt."

The device utilizes a cast steel, internal, toothed rotating ring with teeth corresponding to the cutouts in the flange of the male end. The teeth of the male and female ends are of a form incorporating a bevel and a flat, or a bevel and a slope. The wedging action of the bevels produces good alignment and compresses the gasket to form a tight seal. The female end of the cast steel rotating ring also has a gear sector on its outer surface. This gear sector mates with a steel pinion gear, with two-directional limit stops and hexagonal head, that is used for application of the driving forces.

\section{-Evaluation-}

The main disadvantages of this device for FTR use are the large diameters and the possibility of galling at the wedging interfaces. It is also possible that seal damage will result from movement of the seal as the gear is rotated when making the closure.

\section{-Recommendation-}

Because of the large diameter inherent in this clamp design, it is not recommended for use in the FTR top face open test position and closed loop static mechanical sealing mechanism. 

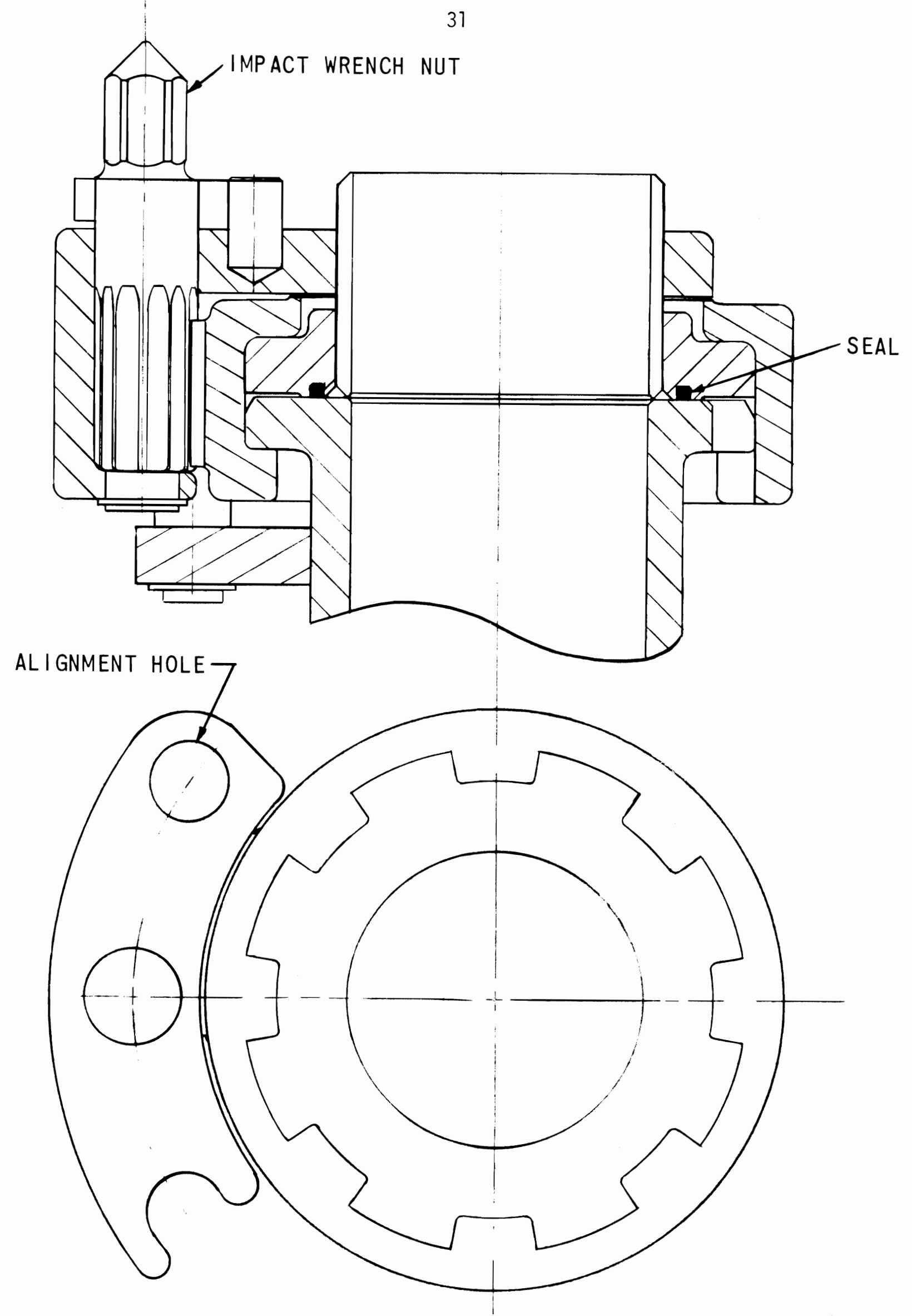

FIGURE 11. Remote Operating Coupling 
Hanford Clamp

\section{-Description-}

The Hanford clamp, shown in Figure 12, obtains the axial force required for a leak-free closure by torquing a single heavy-duty stud and impact wrench nut configuration. This torquing action causes axial movement of three equally spaced hooks. The hooks, in turn, engage a boss on the pipe and transmit the force required to initiate a seal.

-Evaluation-

This clamping mechanism has two advantages that make it appear attractive for FTR. application. First, the concept was designed specifically for remote use $^{9}$. It has been successfully used in the remote operation applications typical of the irradiated chemical separations industry since 1945. The Redox version of this device, with Armco iron and aluminum gaskets, was tested in sodium at $1050^{\circ} \mathrm{F}$ and $100 \mathrm{psig}^{6}$. It was not designed for the test temperatures, however, and showed generalized and large-scale leakage--probably because of relaxation of the carbon steel hooks.

A similar Redox connector, utilizing Inconel-X hooks, was operated without difficulty in $1500^{\circ} \mathrm{F}$ sodium test loops by Pratt \& Whitney. However, the pipe diameters used by Pratt \& Whitney did not exceed one inch.

The Hanford clamp has an advantage in that relatively small diameters are required for this clamp to operate. The ratio of the maximum operating envelope diameter to the pipe diameter is lower than that of the split-C and standard bolt flange clamping concepts reported.

Disadvantages of this connector include irregular seal loading and the comparatively great jaw length.

-Recommendation-

Because of the long jaws of this design and the fact that the design has not been optimized for compact lattice operation, the Hanford clamp is not recommended for use in the FTR top face open test position and closed loop static mechanical sealing mechanism. However, there are several modifications that would make this concept more attractive for FTR use. These modifications are shown on drawing SK-3-12989. The latching shown there is performed on the I.D. of the nozzle and the jaw lengths are greatly reduced. 


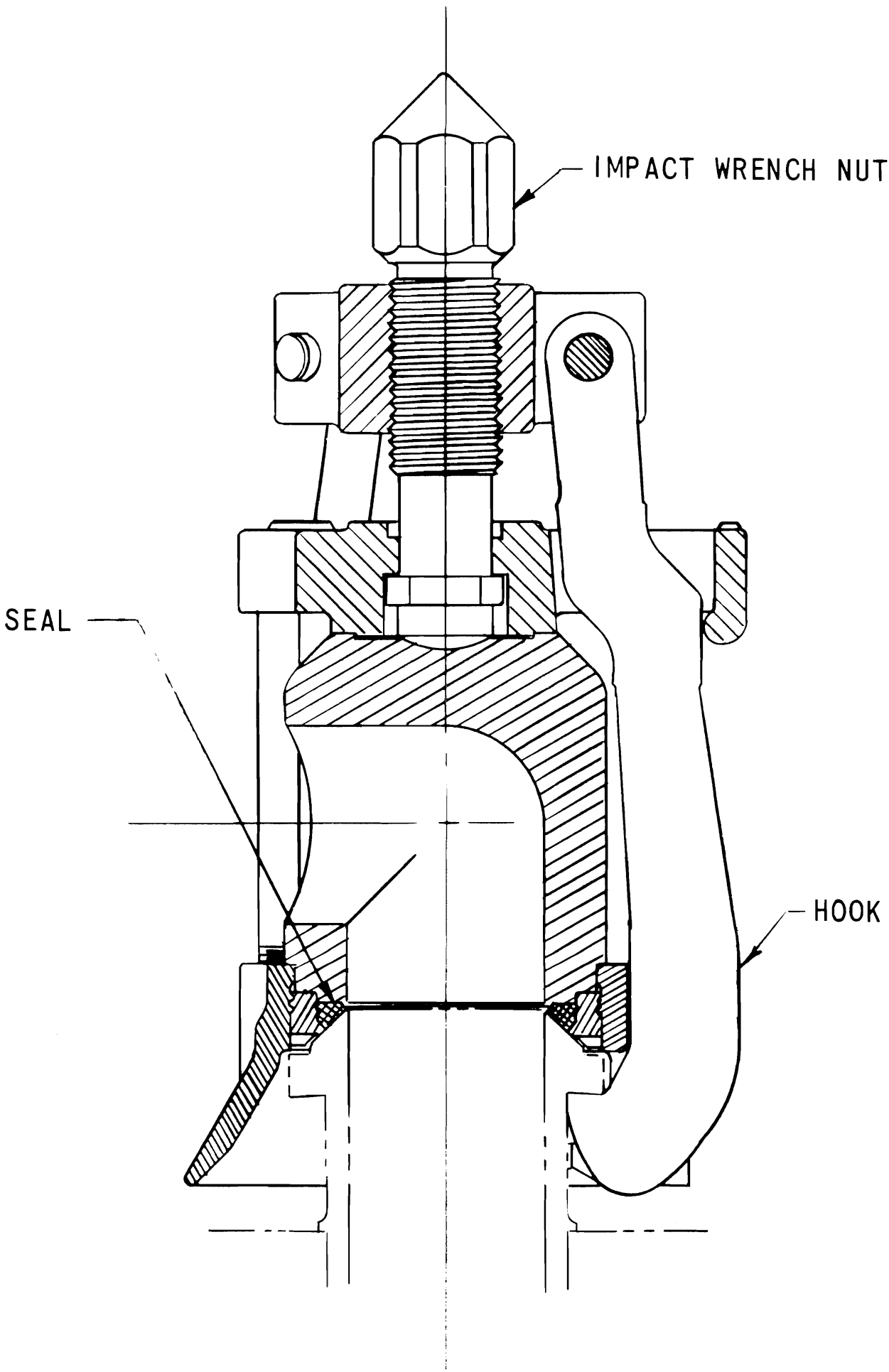

FIGURE 12. Hanford Clamp 


\section{Quick Disconnect}

\section{-Description-}

A quick disconnect design, shown in Figure 13, that obtains the required axial force from an initial load was designed as a tube closure device. It could be redesigned for application as a piping connector.

In operation, the device is lowered into the tube. Downward movement of the device is stopped by the contact of the sealing plate (0-ring) and the tube sealing ledge. Upon being forced downward, the cam and toggle linkage mechanism is actuated to engage the locking tongues and groove by outward radial motion of the tongues. Continued motion results in the seal plate being forced downward against the sealing ledge, compressing the 0-ring gasket, and thus effecting closure. Slight overtravel in the toggle mechanism prevents unseating and unlocking due to internal pressure against the sealing plate. Unlocking and withdrawal of the device is accomplished by reversing the above process.

\section{-Evaluation-}

This device has been tested to $1050^{\circ} \mathrm{F}$ in sodium at $20 \mathrm{psig}^{10}$. The operating principles of the design as shown, when considered for FTR top face clsoure remote application, are uncomplicated and consequently attractive. However, this concept has a number of disadvantages that must be considered. The axial output force is not as high as that attainable with other concepts. The space requirements necessary to route piping and instrumentation leads would probably be restrictive. The axial output force would not be constant as a function of temperature.

\section{-Recommendation-}

Because of the disadvantages listed above, the quick disconnect is not recommended as a clamping candidate. However, the potential of this concept could be better realized with the following modifications:

- Make the linkage less complicated.

- Change the method of loading from thread induced to Belleville spring induced.

- Modify the plug to incorporate necessary electrical and tubing connectors.

The results of these modifications are presented on the following pages in the discussion of the Creep-Compensating Connector. 


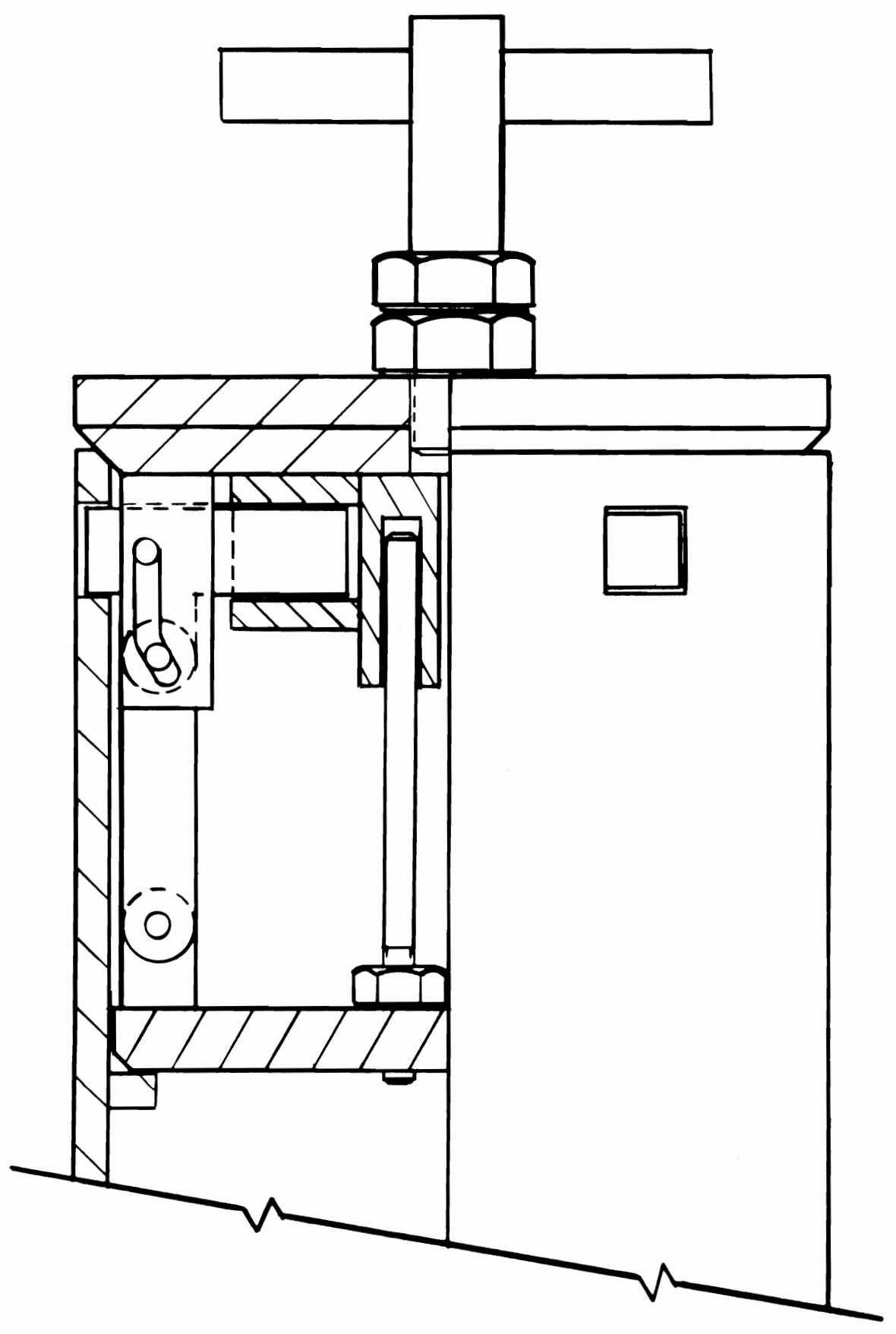

FIGURE 13. Quick Disconnect 


\section{DEVELOPMENT OF THE CREEP-COMPENSATING CONNECTOR}

\section{DESCRIPTION}

The results of the survey of clamping devices have led to the incentive to develop a new clamping design incorporating proven components to meet the static mechanical sealing problems of the FTR top face closed loop and open test position closures. Such a design is shown on drawing SK-3-14608, Reactor Nozzle Connector, Internal Latching, Creep Compensating. The connector is shown in the normal, released, free, and over pressure positions. This design features the internal latching principle of the Quick Disconnect (Figure 13) and the Belleville spring used on the Dome Seal (Figure 10).

The AEC has applied for a patent on this device. The inventors are listed as J. W. Kolb and B. G. Smith. The description is extracted from the patent application as follows:

The creep-compensating quick disconnect compersates for thermal expansion and creep with a minimum of moving parts. The dimensions of the connector occupy a minimum amount of space necessary for close nozzle spacing. A greater pressure on the mechanical seal can be applied without the galling problems associated with threaded devices. A combination of Belleville washers is compressed to provide a loading that is distributed uniformly to the gasket by a pressure ring. This device also acts as a pressure relief valve to help withstand the 'design basis accident'.

The design of this connector is based on the force supplied by a partially compressed Belleville washer. The latching feature is connected directly to the pressure ring (15)* and moved to the lock or unlock position by the sleeve ring. The latches (three required) have a hardened cam surface (1) that works against the tapered surface of the sleeve ring (2).

\footnotetext{
Numbers in parentheses refer to corresponding numbers on drawing
} SK-3-14608, shown in Appendix À. 
The hydrautic cylinder (3) has a 1" stroke and develops 100,000 pounds of force. It is modified by an adapter (4) fixed to the housing (5) of the cylinder, and by a "U" piece extension (6) attached to the piston. Mating the adapter to the spline end piece (7) of the pressure ring, after guiding it into place, is achinver by a $1 / 4$ turn clockwise. Pressure applied to the cylinder is then transferred through the "U" piece to the sleeve (8), thereby compressing the Belleville and releasing the latches (9). Retraction of the latches is made by the small Belleville washer (16) [held in position with a retaining ring (17)] when the cylinder compresses the larger Belleville washers. Removal of the connector is made by lifting the cylinder away from the nozzle.

The connector installation is much the same as removal. The cylinder is connected in the same way: the connector is guided in place by the cylinder; pressure is released from the cylinder; and a $1 / 4$ turn counterclockwise frees the cylinder for removal.

The basic parts of this device are the four Belleville washers, the three latches that are attached to the body with dowe 1 pins, a pressure ring threaded to the body and welded (10) in place after adjustment, a sleeve ring, a small Belleville, and a retaining ring.

The pressure ring is so named because it transmits the pressure from the Belleville to the gasket that seals the connector to the nozzle (11). The body houses the electrical plugs and instrument leads (12). At the opposite end of the body is the spline that mates with the cylinder adapter (13). 
The connector is guided in place in the nozzle and the electrical plug aligned with a key and key slot. The latch is forced out in lock position by a cam surface on the body of the connector. When the latches are locked, they carry the load in direct shear. The latches and body guide the movement of the sleeve ring. The latches are pinned to the sleeve with a $0.24 "$ pin (14).

The connector will develop 50,000 pounds in the locked position. The pressure needed for the Grayloc seal is 25,000 to 30,000 pounds. The Grayloc seal is a metal seal ring with two tapered seal surfaces projecting from the flange (10). The seal surfaces match with machined seal surfaces on the nozzle and pressure ring, with a slight difference in angle, and make a seal when forced together. This assembly is designed to withstand 100,000 pounds pressure with no deformation.

\section{RECOMMENDATION}

It is recommended that a prototype of the creep-compensating design concept be designed and fabricated and subjected to a development testing program in conjunction with selected seals and joints as a prime candidate for the FTR open test position and closed loop static sealing mechanism. The creep-compensating connector has been conceived to overcome or avoid the major drawbacks encountered in the other types by providing such features as thermally compensated uniform seal loading, remote operability in a small space, accommodations for piping and instrument leads, and freedom from boltthread problems. 


\section{SURVEY OF STATIC METAL SEALS AND JOINTS}

There are many methods of static metal-to-metal sealing that can be applied to prevent or extremely limit the flow of fluids, gases, or particles across an intended barrier. Most of these mathods fall into one or a combination of the three following categories: metallurgical seals, elastic deformation seals, and plastic deformation seals.

The metallurgical seal has previously been discussed under clamping devices. This seal can be in the form of a welded, brazed, or bonded joint. It obviously represents the most leak-tight seal because the leakage holes are reduced to grain boundary widths. Metallurgical seals for FFTF will be reported in a later document.

The elastic deformation seal is characterized by having no stresses in the sealing mechanism that exceed the yield point of the material. Hence, the material remains undeformed from previous usage. In ideal operating conditions, this design concept enables repeated appiication of an individual seal. However, for high temperature and high pressure applications, there are few purely elastic seals in operation.

The plastic deformation seal is characterized by flow of the seal interface material. This flow is the result of temperature, pressure, and compression or a combination thereof. The seal material flows to fill the surface irregularities of the adjacent parts. These seals are specifically designed for very high temperatures and high pressures. Seals in this category are not suitable for much reuse since they depend entirely on a region of plastic flow for sealing. The fused seal, indented seal, metal 0-ring, freeze seal, and flat metal gasket seal are examples of plastic seals. 
In a combination-elastic-plastic deformation seal, the actual sealing surface undergoes localized flow, but other parts of the gasket are only elastically deformed and thus can flex and adjust the sealing surface for small displacements during vibration or in response to bending loads. As a result of the localized plastic flow, the seals in this category will exhibit a low probability of reuse. Because of the adaptability of these seals to conditions of prolonged high temperatures, large thermal gradients, and some mechanical loading, it appears that logical FFTF seal candidates will emerge from this category. The Grayloc, Conoseal, Hydrodyne, K-Seal, and Four-Point are examples of elastic-plastic seals.

In general, it is concluded that there are enough seal and joint designs within the current state-of-technology that an acceptable candidate shall emerge. Promising candidates from each seal and joint grouping are recommended for application to the FTR in the discussions that follow. 


\section{$\underline{\text { HIGH LOAD SEALS }}$}

For the purposes of this report, the various seals and joints surveyed have been grouped into high load seals and low load seals. The loads required to effect a seal vary over a wide range. The division point was quite arbitrary. However, in general, the high load seals display less resilience and more deformation than the low load seals.

Four-Point Seal

\section{-Description-}

A four-point seal design, shown in Figure 14, utilizes a combination of plastic and elastic deformation to initiate a seal. The plastic and elastic deformation results from application of compressive forces. The design consists of a solid four-point ring made of Armco iron. The seal is made so that is has a cross section with two sides parallel and two sides concave.

-Evaluation-

This design, with four sealing edges, has proved satisfactory when subjected to thermal cycling to $450^{\circ} \mathrm{F}$. This seal was designed by the Nuclear Development Corporation of America when none of the commerically available metal 0-rings tested provided satisfactory seals ${ }^{10}$.

-Recommendation-

Because of previous success of this seal, the four-point seal is recommended as one of the seal/joint design candidates for the FTR top face open test position and closed loop static mechanical sealing mechanism. 


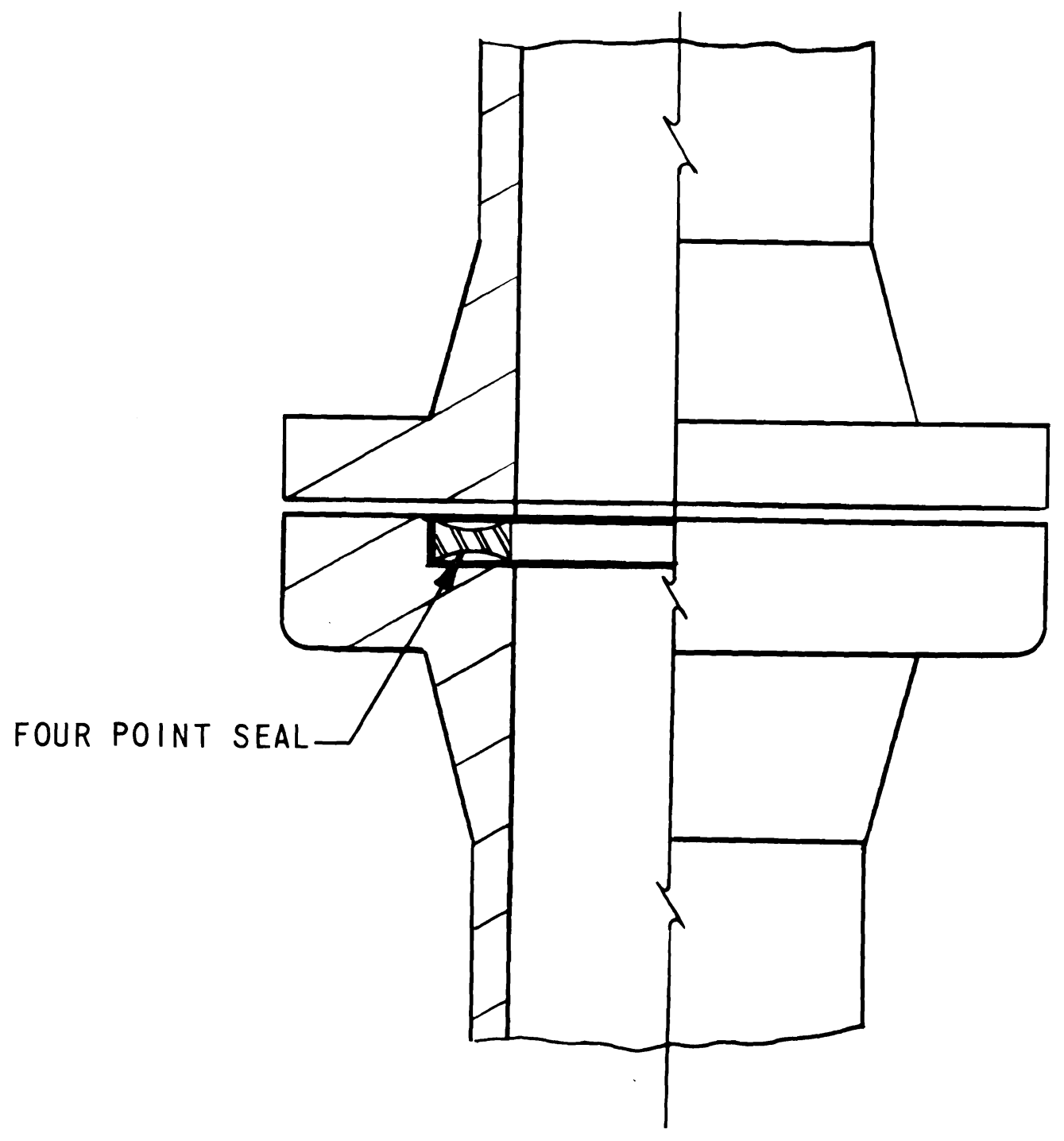

FIGURE 14. Four-Point Seal 
Flat Metal Gasket

\section{-Description-}

A flat metal gasket design, shown in Figure 15a, utilizes plastic deformation from application of compressive forces. The design of the mating flanges has a large effect on the leakage characteristics of gasket seals. The flat surface flange faces allow the gasket to flow outward under compression. The design, while economical, is not suited for high pressure applications. The grooved surface flange of Figure 15b directs most of the plastic flow of the gasket material upward into the surface irregularities of the mating flange. The stepped flange design of Figure $15 \mathrm{c}$ retains the advantage of an enclosed gasket design, but also has the advantage of limiting the thermal and mechanical forces on the gasket. This design also enables the gasket and mating flanges to be positively positioned and the compression can be controlled by allowing the flange faces to contact when proper compression is achieved.

\section{-Evaluation-}

The thermal transients and dynamic forces are the prime modes of failure for flat metal gaskets which are characterized by low resiliency ${ }^{11}$. Several modifications to the flat metal gasket itself have been tested in liquid sodium environments. A typical modification consisted of machining concentric grooves on the joint faces. One of the benefits of this modification is the resultant reduction in the area of plastic flow necessary to form a good seal, thus reducing the total clamping force requirements. Results of the testing indicate improved seal performance by incorporation of the concentric groove geometry ${ }^{12}$.

-Recommendation-

Because of the previous success of the annealed nickel gasket when used with concentric grooved joint faces, this flat metal gasket design is recommended as one of the seal/joint design candidates for the FTR top face open test position and closed loop static mechanical sealing mechanism. 
44

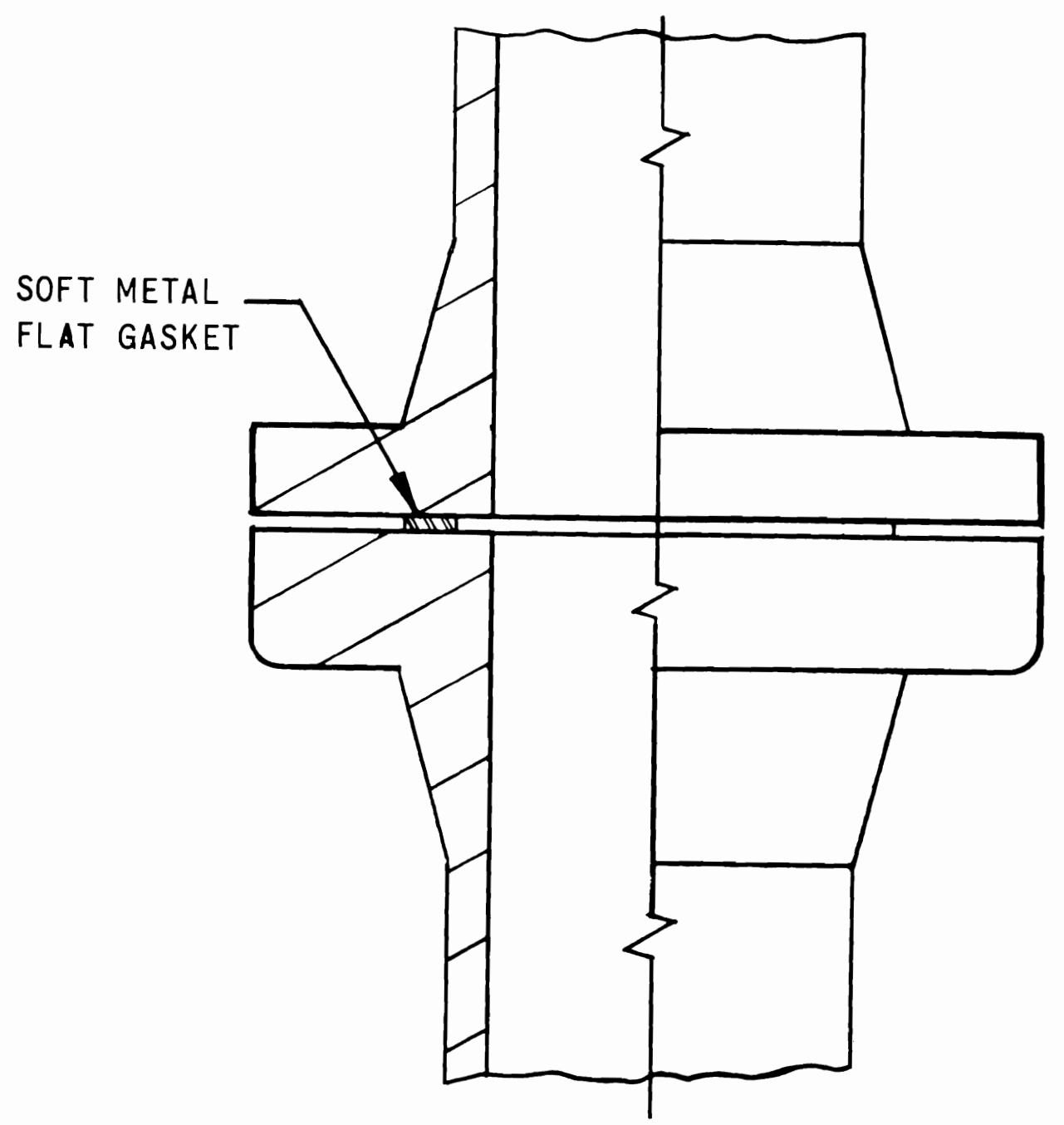

FIGURE 15a. Flat Metal Gasket 


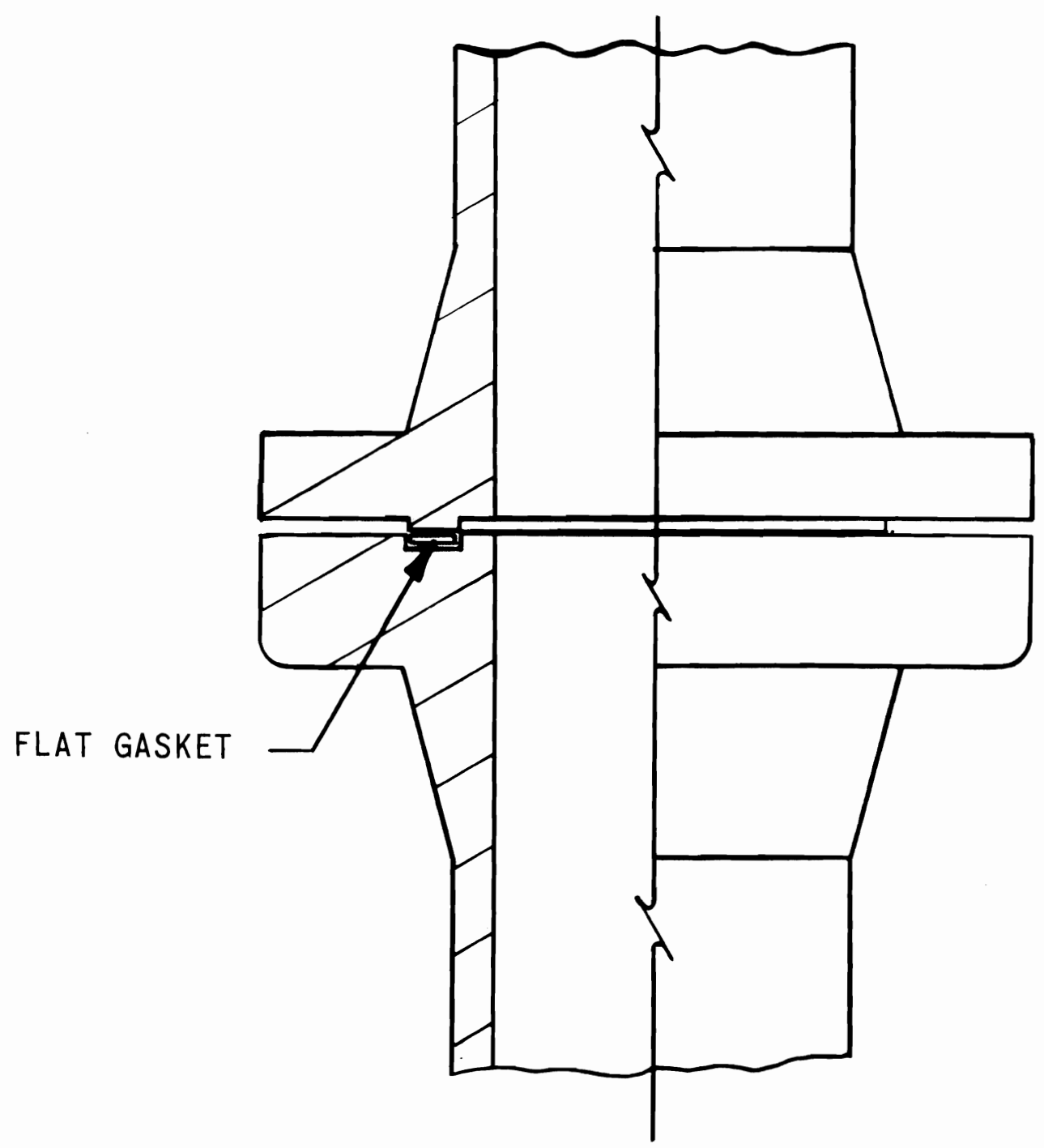

FIGURE 15b. Grooved Surface Flange 


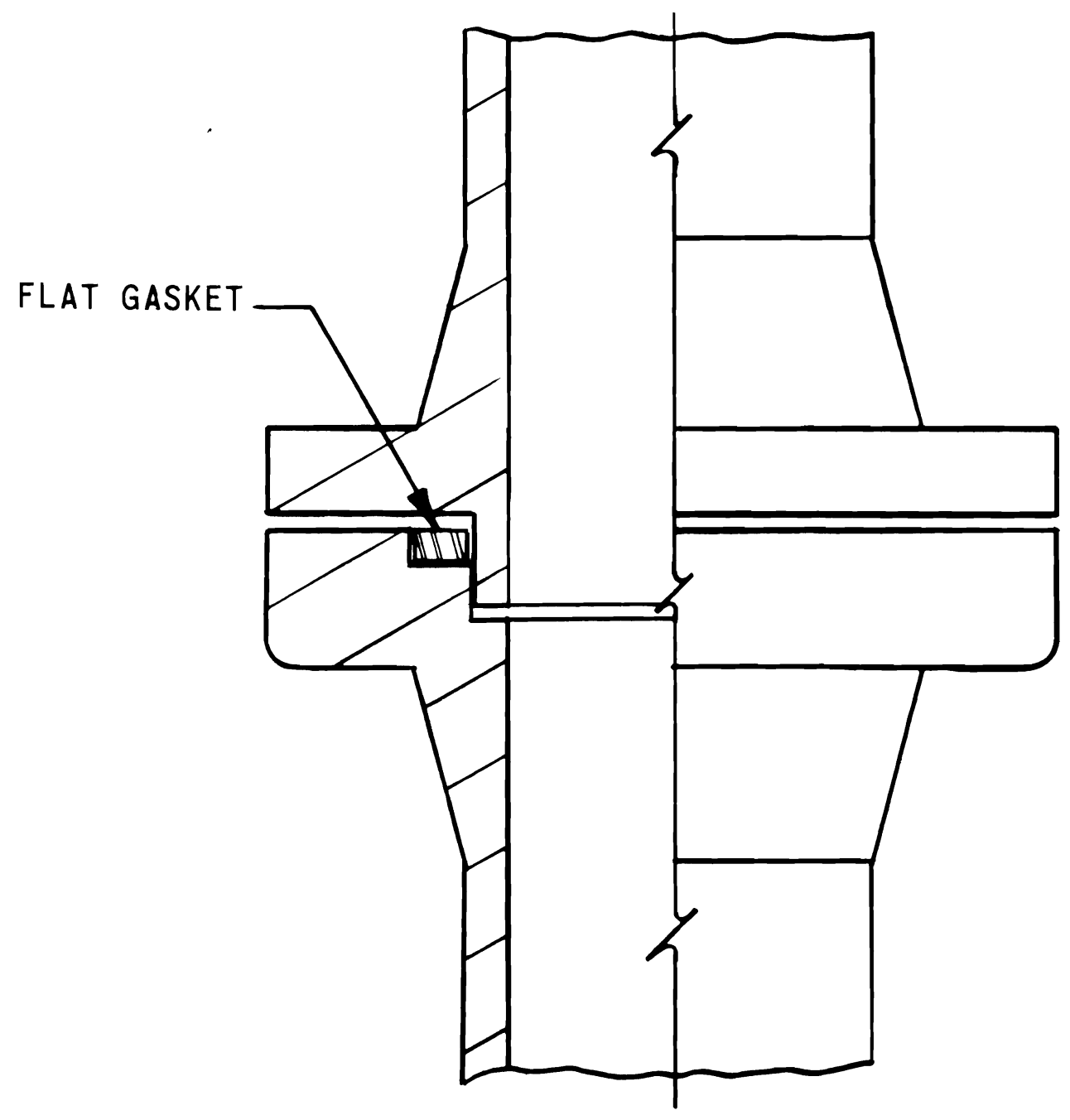

FIGURE 15c. Stepped Flange 
Grayloc Seal

-Description-

A Grayloc seal design, shown in Figure 16, utilizes a combination of plastic and elastic deformation to initiate a seal. The plastic and elastic deformation result from application of compressive forces. These forces are transmitted through the wedging action of the Grayloc clamp. The sealing lines of contact are at the extremities of the arms of the T-shaped (cross-section) seal ring. The angle of the T-arms and the angle of the sealing surfaces of the flange are slightly different so that the tips of the T-arms make contact first, and are radially loaded as the flanges are moved axially together.

A Grayloc flange configuration utilizing two separate seals, a primary and secondary seal with a gas filled chamber in between, has been recommended by Atomics Internationa ${ }^{14}$ for further investigation by BNW. In this configuration, as shown in Figure 17, the primary seal is not in direct contact with the flowing sodium. This minimizes the effects of thermal shocks and permits the use of other materials for the primary seal.

The Gray Tool Company has designed a special Grayloc Dual Seal Ring, shown in Figure 18. In this design, the primary seal contains the system pressure. The secondary seal is for leak monitoring.

-Evaluation-

Tests of the standard Grayloc seal have been conducted for sealing helium at temperatures to $1000^{\circ} \mathrm{F}$ and pressures up to $375 \mathrm{psig}^{13}$. Grayloc seals have also been used in small loops and large static sodium pots throughout the industry with good success. The major disadvantages of the Grayloc joint for FTR application include: large axial clamping forces are required to stress the seal into the elastic range; the seal exhibits an apparent inability to maintain a leak-tight barrier during high magnitude cyclic stresses; and the seal performs best when the surface is plated with a soft metal and lubricated. In sodium service, this requirements could create a materials compatibility problem. -Recommendation-

Because of the previous success of the Grayloc seal, mentioned above, this Grayloc seal/joint design is recommended as one of the candidates for the FTR top face open test position and closed loop static mechanical sealing mechanism. The final seal design, seal loads, and joint design shall be as recommended by the Gray Tool Company. 


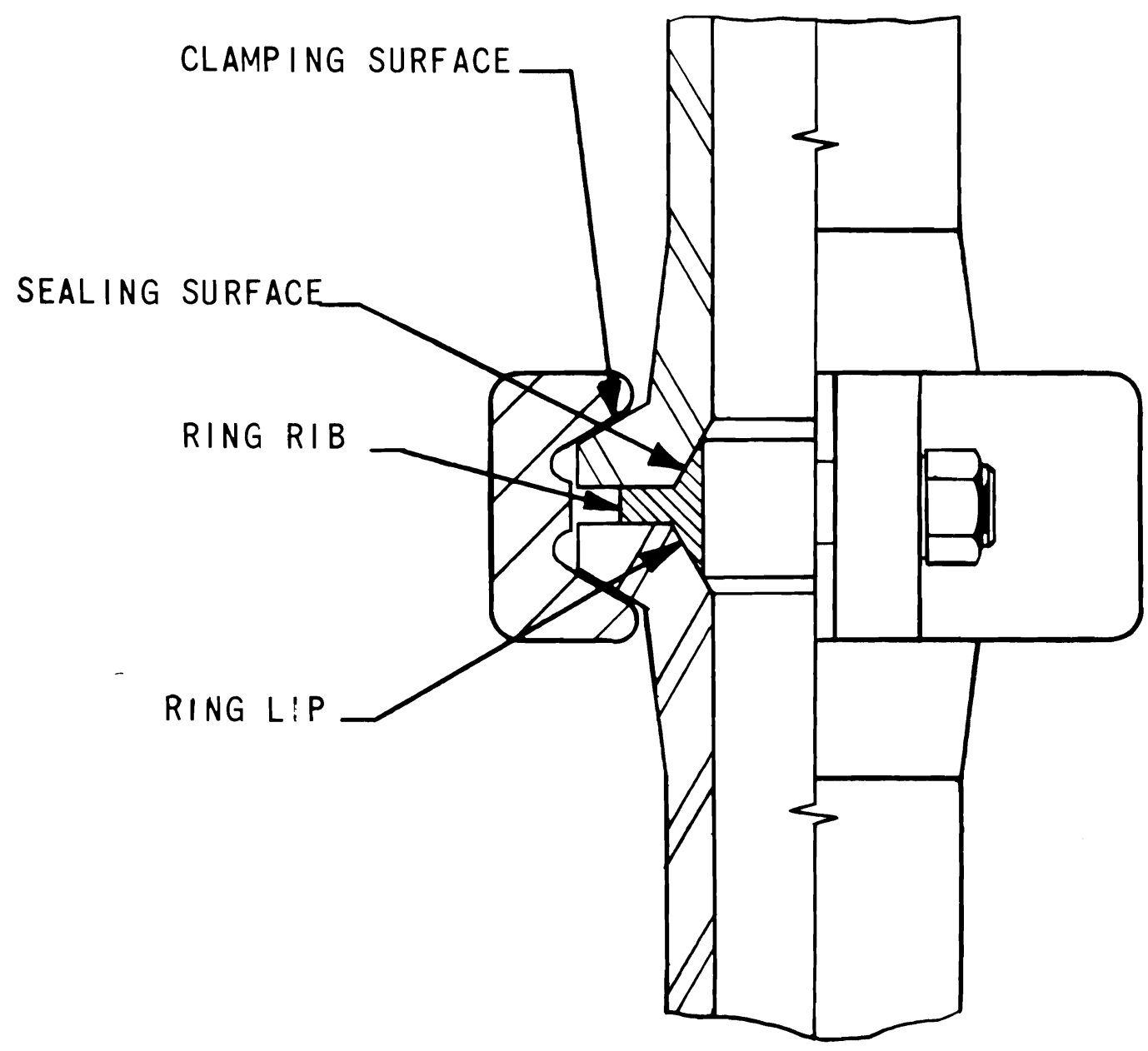

FIGURE 16. Grayloc Seal and Clamp 


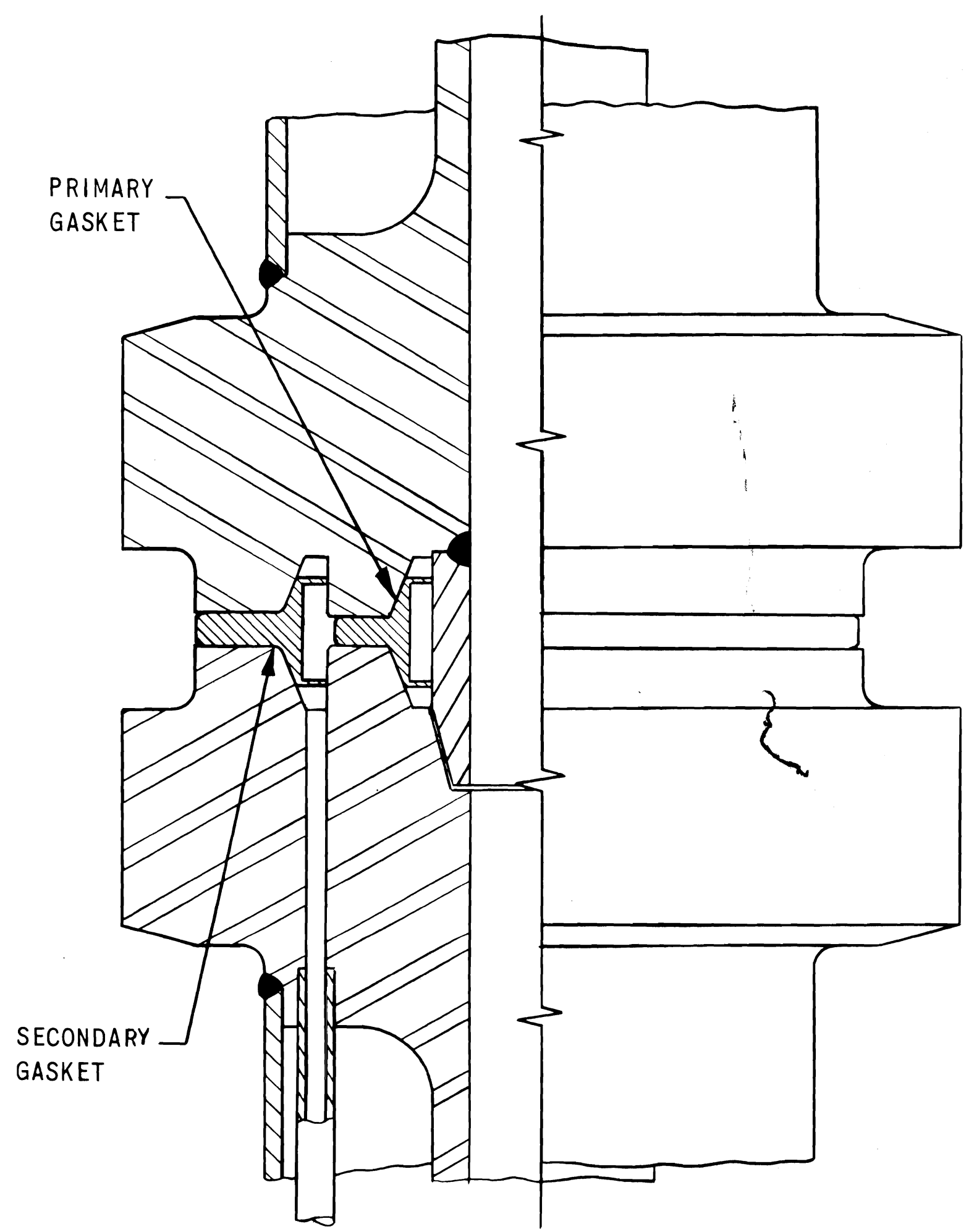

FIGURE 17. Double Grayloc Seal Flange 
PRIMARY SEAL

\section{SECONDARY SEAL}

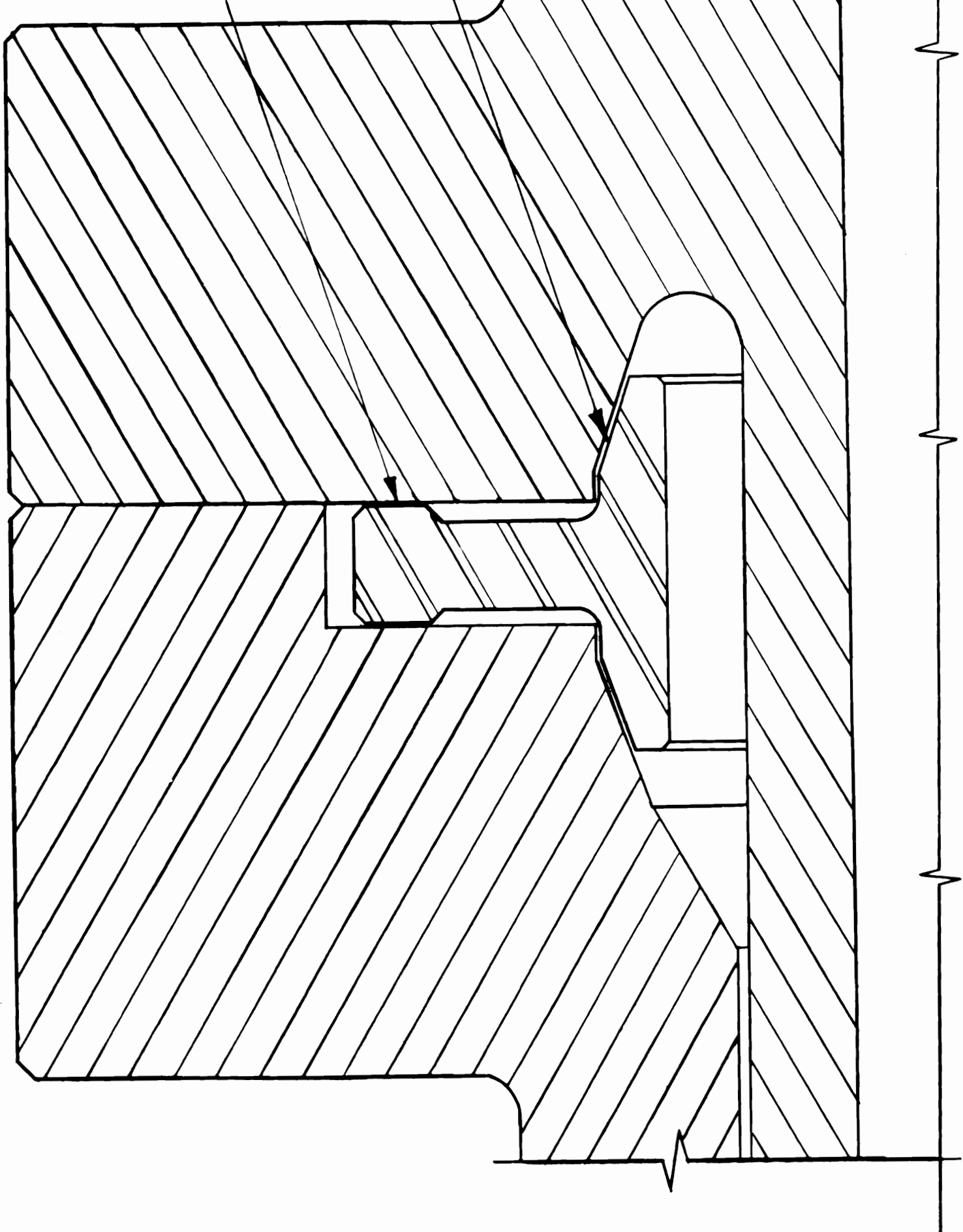

Figure 18 Grayloc Dual Seal 


\section{Lens Seal}

-Description-

A lens seal of German design, shown in Figure 19, utilizes plastic and elastic deformation to initiate a seal. The deformation results from application of compressive forces and temperature. As the flange clamping load is increased due to an increase in temperature, the additional force, which normally would cause additional plastic deformation of the sealing surfaces, is actually dissipated in radially compressing the gasket. The gasket does not undergo permanent radial deformation and, therefore, springs back to its normal shape as the clamping forces are released.

-Evaluation-

The design has been used successfully at pressures to 3000 psig and temperatures to $1100^{\circ} \mathrm{F}$. However, no documentation of tests in a liquid sodium environment was discovered. A combination of lens and Grayloc seals double flange, shown in Figure 19, has been recommended for FFTF by Atomics International for further investigation by BNW.

Some of the disadvantages of this seal include: The wedging action produced as temperature is increased creates the possibility of self-welding. This same wedging action which complements the seal at high temperature could be detrimental in a thermal cyclic environment. Surface finish and parallelism must be better than in purely plastic deformation designs. Internal pressure forces are not used to assist in forming a seal.

-Recommendation-

Because of the predicted rapid thermal cyclic environment of the FFTF, the Lens Seal is not recommended for use in the FTR top face open test position and closed loop static mechanical sealing mechanism. 


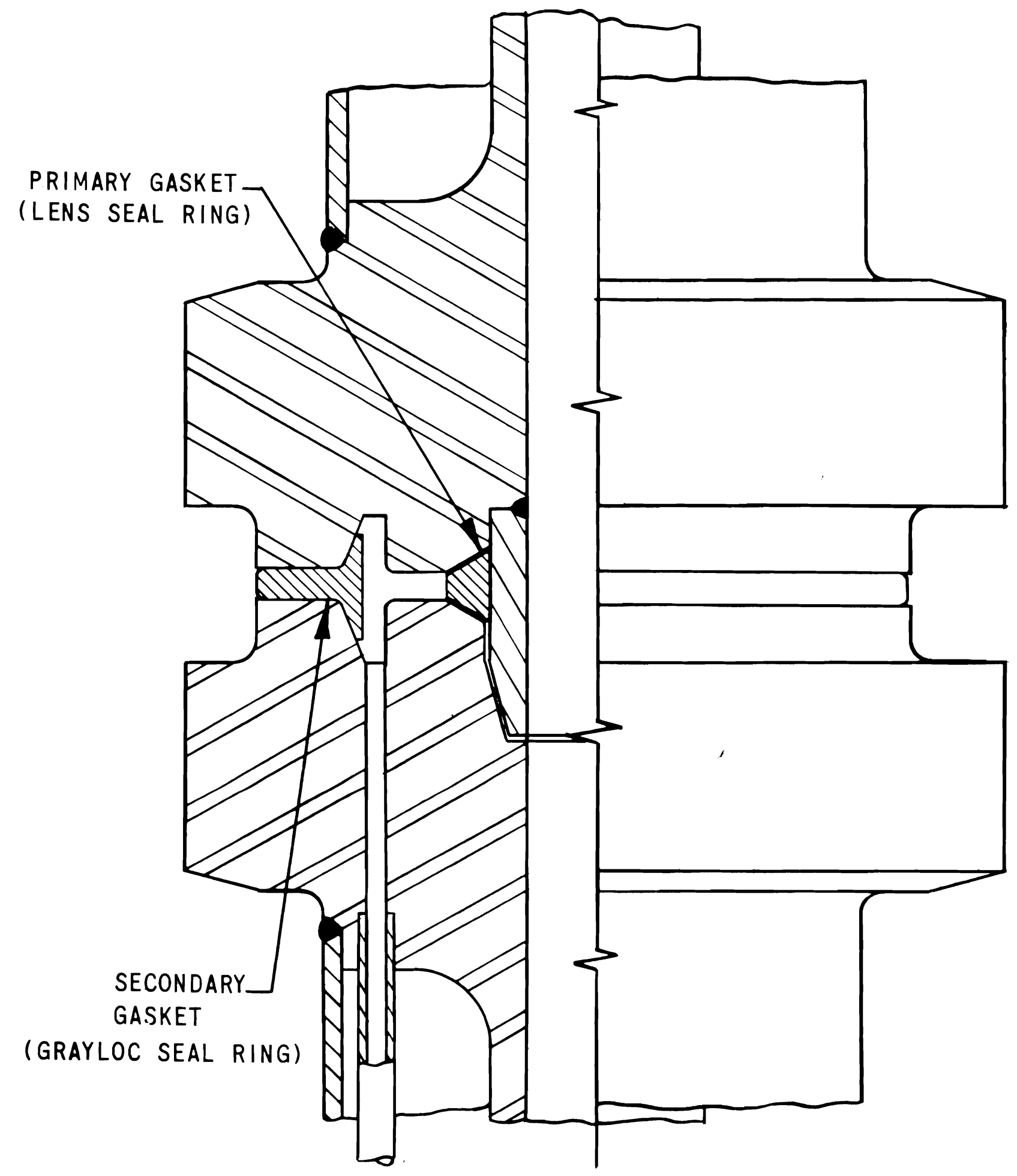

FIGURE 19. Lens and Grayloc Seals Double Flange 


\section{Indented Seal}

\section{-Description-}

An indented seal design (Figure 20), using plastic deformation from the application of high compressive forces, was designed and tested by Oak Ridge National Laboratory ${ }^{15}$.

The configuration consisted of a raised tooth of $V$-shaped cross section, machined on the face of each flange. The raised tooth indents a flat soft metal ring to provide a tight seal when the joint is assembled. The following soft metal ring materials were tested with the Inconel indented flange configuration: dead-soft annealed copper, Armco iron, annealed nickel "A " and nickel-plated Armco iron.

\section{-Evaluation-}

Of the four gaskets tested, the nickel-plated and annealed Armco iron gaskets proved most satisfactory ${ }^{16}$. The Inconel flanges showed no sign of damage from corrosion or mechanical effects. Clamping problems resulted in leakage during temperature fluctuations.

\section{-Recommendation-}

Because of this seal's demonstrated inability to compensate for temperature fluctuations, the Indented seal is not recommended for use in the FTR top face open test position and closed loop static mechanical sealing mechanism. 


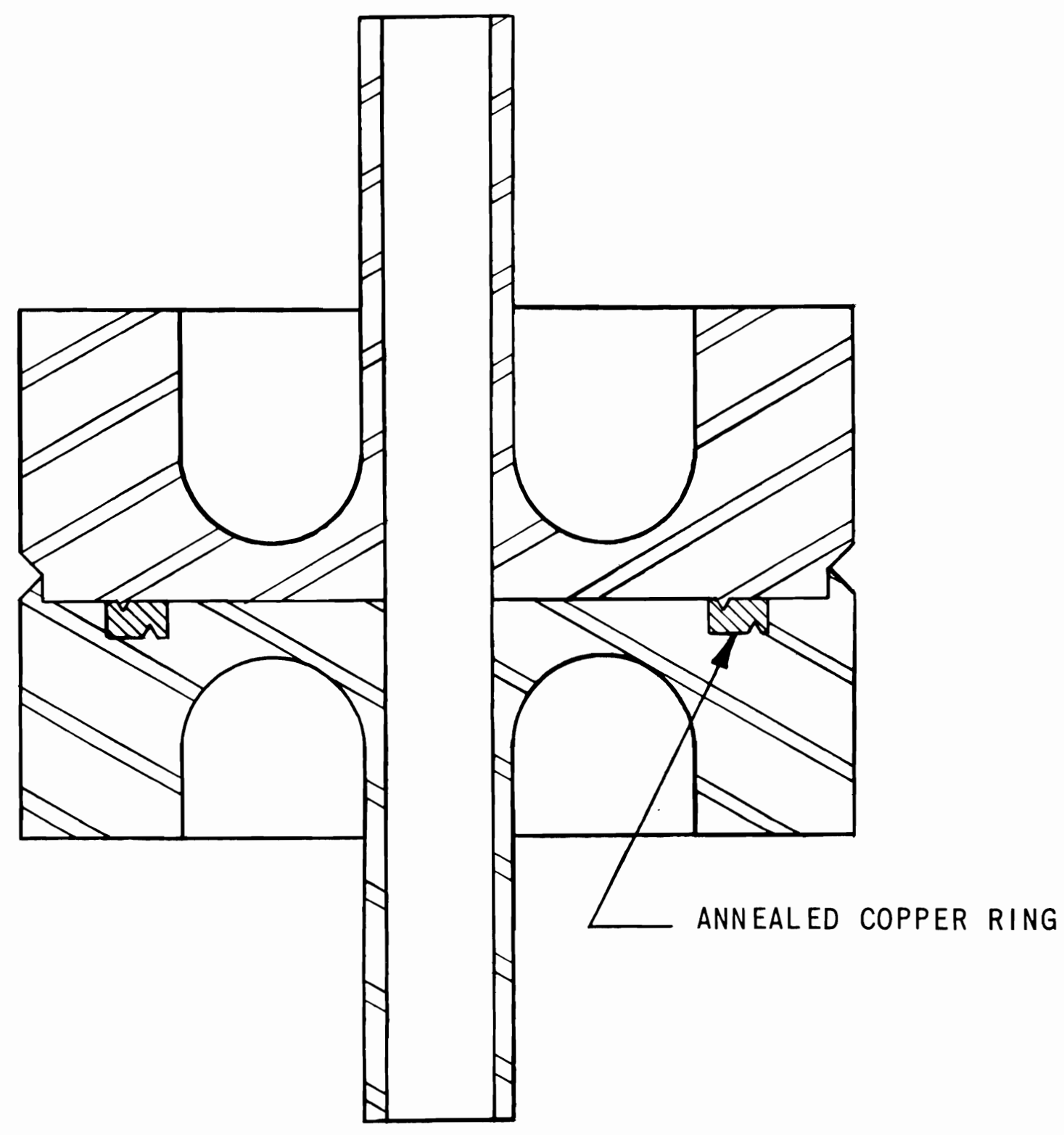

FIGURE 20. Indented Seal 


\section{Metal 0-Ring}

$$
\text { -Description- }
$$

Metal 0-ring designs, similar to the one shown on Figure 21 , have been tested extensively by the Nuclear Development Corporation of America 10 and other laboratories across the country. The solid circular cross section seal operates almost entirely in the plastic deformation range.

\section{-Evaluation-}

In general, the conclusions drawn indicate that circular cross section 0 -rings are not satisfactory seals for sodium service at elevated and rapidly fluctuating temperatures.

\section{-Recommendation-}

Because of the rather unsuccessful performance of this seal design, the metal 0-ring is not recommended for candidacy for the FTR top face open test position and closed loop static mechanical sealing mechanism. 
56

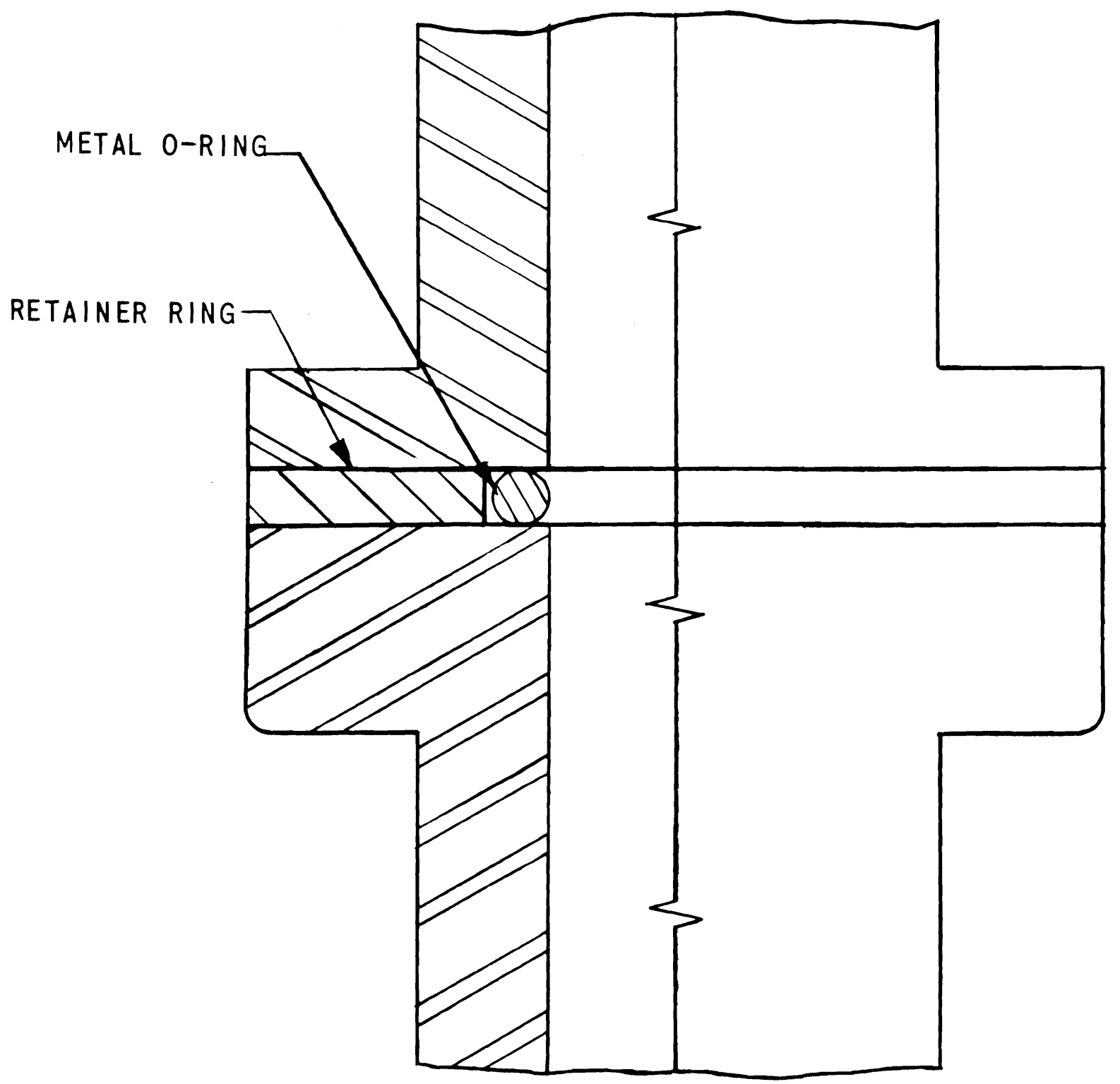

FIGURE 21. Metal 0-Ring Joint 
LOW LOAD PRESSURE-ASSISTED SEALS

The low load seals are characterized by surface deformation (usually a soft coating), resiliency, and precision. A further division of the low load seals is the grouping of sealing concepts into either pressure-assisted or non-pressure-assisted types.

In the pressure-assisted seals, system pressure (internal in the FTR application) augments the natural resiliency of the seals by maintaining continuous pressure at the sealing lines of contact. For some seals in this category, the cross sectional configuration can be made the mirror image to account for either a positive or a negative pressure differential. In another variation of the pressure-assisted seal, the hollow metal 0-ring, the pressure comes from an isolated gas source in the cavity in the center of the 0 -ring.

Hydrodyne Seal

\section{-Description-}

A Hydrodyne seal design, shown in Figure 22, utilizes primarily eiastic deformation to initiate a seal. Localized plastic deformation also occurs when a soft coating, such as nickel, is applied to the seal surface. The deformation results from application of compressive clamping forces and internal pressures. The compression of the seal in its cavity provides a leak-tight fit due to embedding the edges of the seal into the cavity walls. The seal is supplemented at operating pressures by the internal pressure expanding the seal. This expansion assists in maintaining positive seal contact.

-Evaiuation-

This design has proved satisfactory when subjected to thermal cycling gas environments. Surface finishes, parallelism and flatness of mating surfaces, and good flange design are more critical with this design than with a design using purely plastic deformation. The seal has a small cross-sectional area.

\section{-Recommendation-}

Because of previous success of the seal in thermal cycling environments, the Hydrodyne Seal is recommended as one of the seal/joint design candidates for the FTR top face open test position and closed loop static mechanical sealing mechanism. The final seal material, seal loads, and joint design shall be as recommended by the Donaldson Company, Inc. 


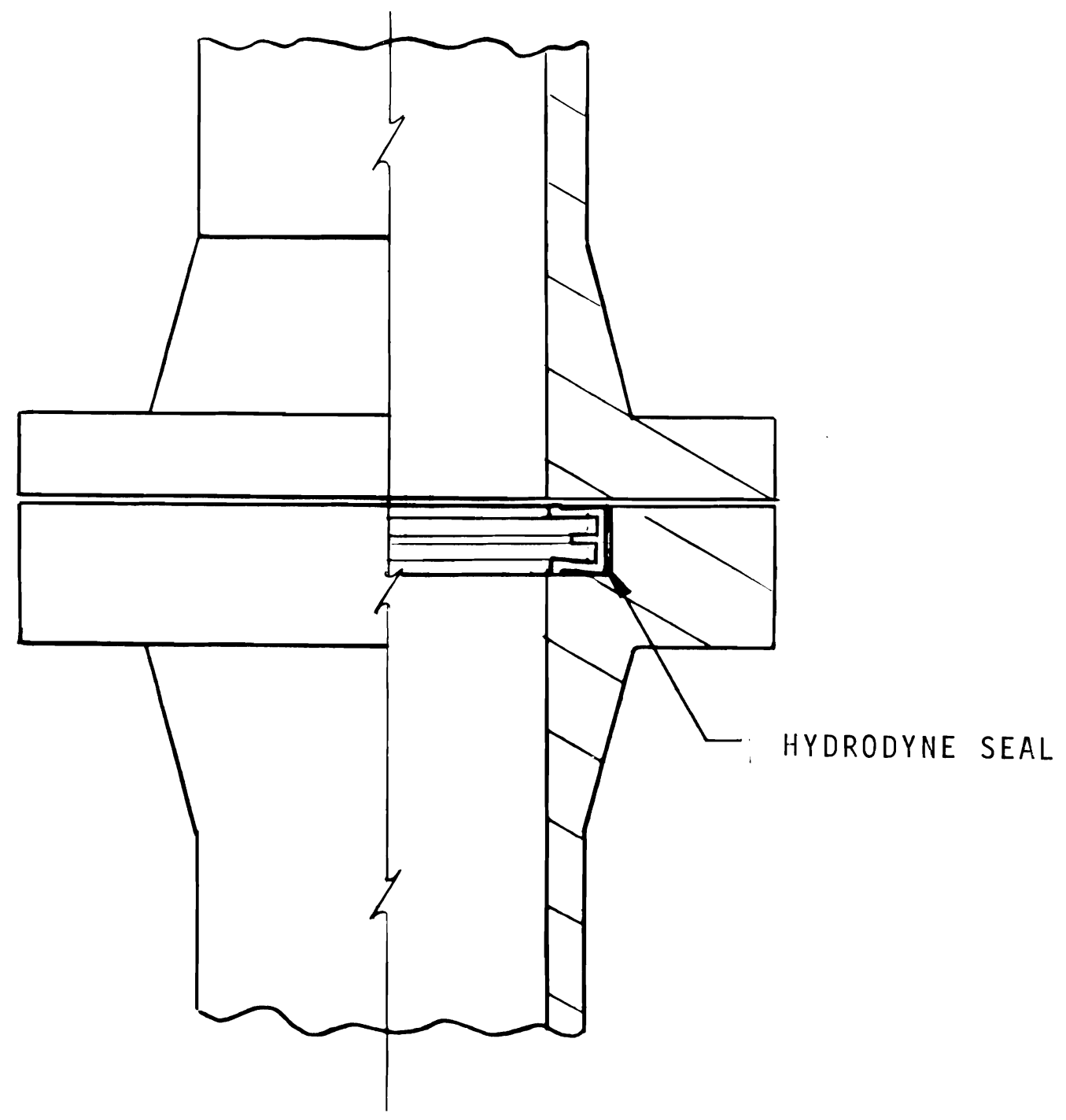

FIGURE 22. Hydrodyne Seal 
$\underline{K-S e a 1}$

-Description-

A K-seal design, shown in Figure 23, utilizes a combination of plastic and elastic deformation to initiate a seal. This deformation results from application of compressive clamping forces and internal pressures. The compression of the seal in its seat provides a leak-tight fit due to embedding the edges of the seal into the cavity walls. The seal is supplemented at operating pressures by the internal pressure expanding the seal. This expansion assists in maintaining positive seal contact.

\section{-Evaluation-}

This design, with four sealing edges, has proved satisfactory when subjected to thermal cycling. However, this design must be used with caution under long-term cyclic environments due to the possibility of fatigue failure. Better surface finish and parallelism than necessary for the purely plastic deformations are required for effective sealing. By its very nature, this seal also requires more careful handling than would a design of more compact cross section. The seal has a small cross-sectional area.

No documentation of test data in liquid sodium for this configuration was discovered. However, it has been used successfully in irradiated chemical separations to temperatures of $350^{\circ} \mathrm{F}$ and pressures of 100 psig 17 . The seals have also been used in other applications to temperatures of $1800^{\circ} \mathrm{F}$ and pressures of 1000 psig.

\section{-Recommendation-}

Because of previous success of this seal in thermal cycling environments, the $\mathrm{K}$-seal is recommended as one of the seal/joint design candidates for the FTR top face open test position and closed loop static mechanical sealing mechanism. The final seal material, seal loads, and joint design shall be as recommended by the vendor. 


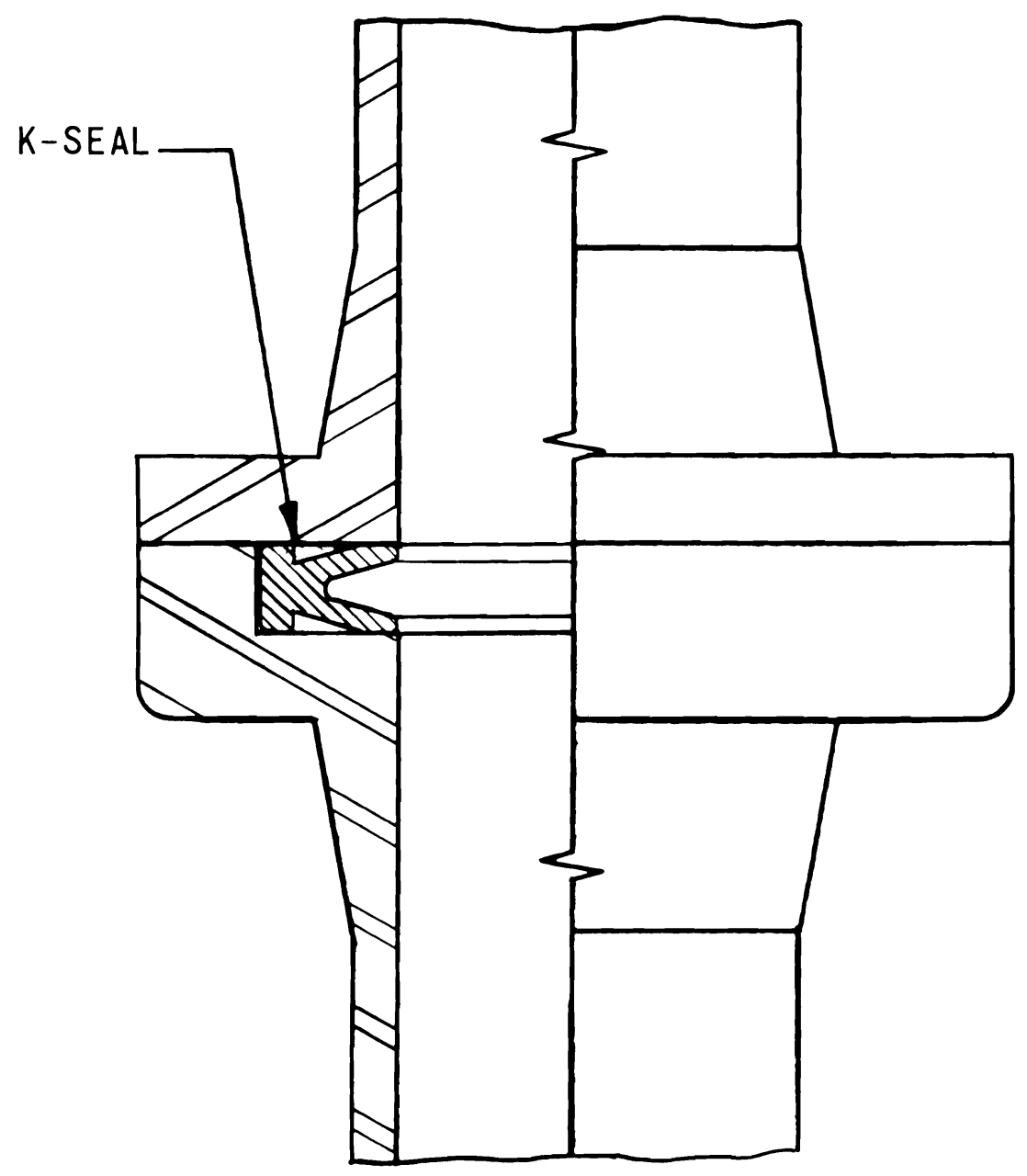

FIGURE 23. K-Sea 1 
Hollow Metal 0-Ring

-Description-

Hollow, gas-filled, circular metal 0-rings have been used for high temperature applications. This type relies more on elastic deformation characteristics. At elevated temperatures, the gas pressure increases, offsetting the inherent loss of strength in tubing at high temperatures and actually increasing the resilience.

-Evaluation-

The main disadvantages of this design are inability to seal high pressures, and unreliable manufacturing techniques.

-Recommendation-

Due to rather poor previous experience of this seal in high pressure sodium appiications, the hollow metal 0-ring is not recommended for use in the FTR top face open test position and closed loop static mechanical sealing mechanism. 
LOW LOAD NON-PRESSURE-ASSISTED SEALS

The individual members of this category, like the low load pressureassisted seals, are also characterized by a high degree of natural resiliency; but they are not assisted by system pressure.

Conoseal

\section{-Description-}

A Conoseal design, shown in Figure 24, utilizes a combination of plastic and elastic deformation to initiate a seal. These forces are transmitted through the wedging action of the conoseal clamp. The initial gasket angle is greater than the angles of the mating flange seat faces. As the flanges are brought together, the seal is loaded radially against the mating flange lips. The flange seat surfaces are brought to bear against the seal sides to control buckling. The sealing lines of contact are at the maximum and minimum radii of the seal. The mechanical advantage of the joint design induces a plastic flow condition at these locations.

\section{-Evaluation-}

Tests of this type flange with a single seal have been performed by Atomics International ${ }^{7}$ and the Nuclear Development Corporation of America ${ }^{6}$. From the results of these tests, it was concluded that two-inch Conoseals have a high probability of performing satisfactorily in $1000^{\circ} \mathrm{F}$ liquid sodium systems at stresses to 14,000 psi. Tests have been performed by Oak Ridge National Laboratory on both single and double sealed joints. These configurations were subjected to gaseous helium at temperatures to $1500^{\circ} \mathrm{F}$ and pressures to $300 \mathrm{psig}^{13}$. These tests indicated that 2-1/2 and 10-inch Conoseal joints are reliable after many disassembly and assembly operations in this gaseous helium environment. This reliability statement precludes the use of a new seal with each disassembly and assembly operation. A double Conoseal flange design, shown in Figure 25, has been recommended for FFTF by Atomics International for further investigation by BNW.

The major disadvantages of the Conoseal joint for FTR use are the: critical tolerancing on gasket and seat and the critical alignment required to remotely operate the Conoseal.

\section{-Recommendation-}

Because of the previous widespread success of this seal in sodium applications, the Conoseal is recommended as one of the seal/joint design candidates for the FTR top face open test position and closed loop static mechanical sealing mechanism. The final seal material, seal loads, and joint design shall be as recommended by the Aeroquip Corporation/Marmon Division. 


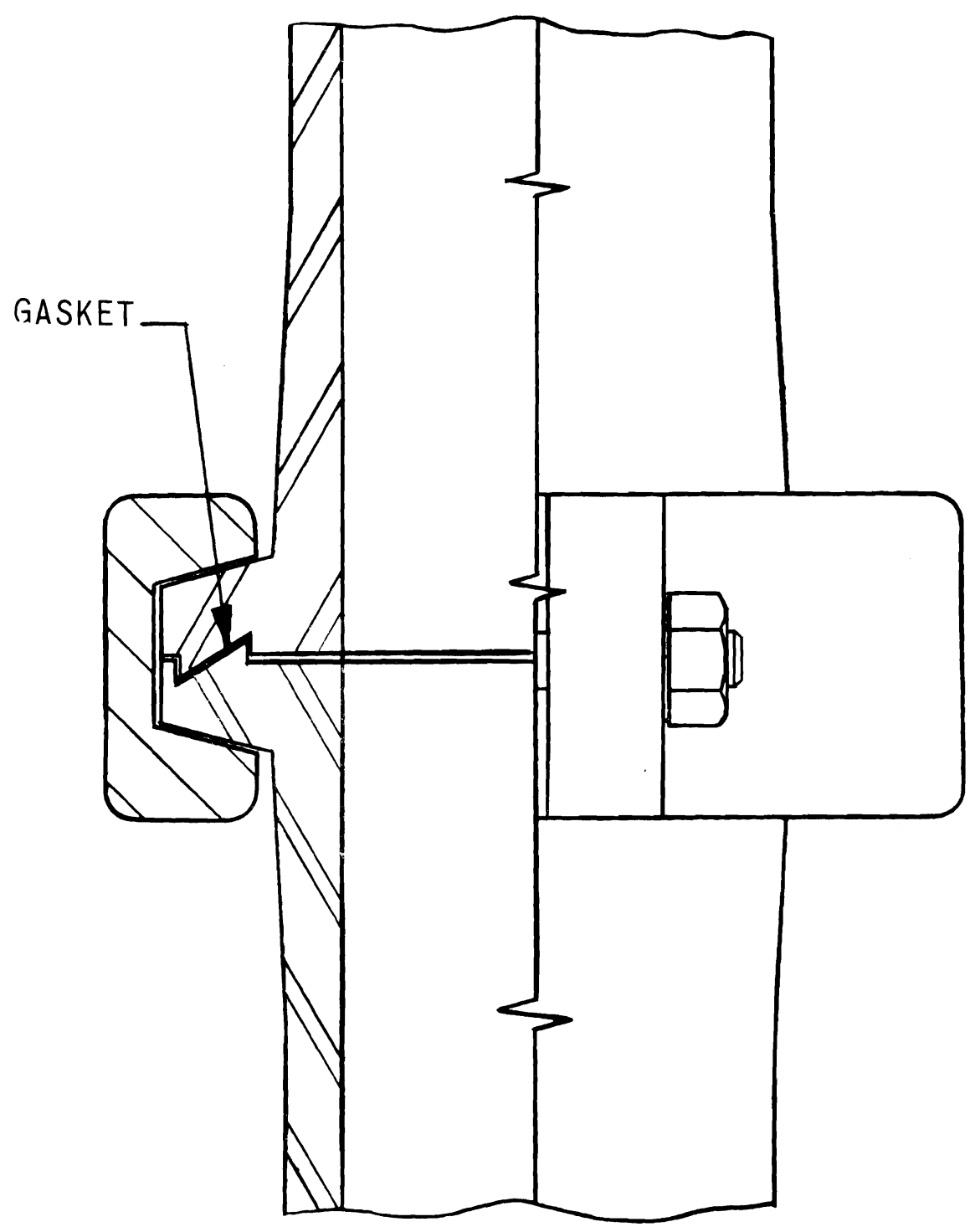

FIGURE 24. Conoseal 
64

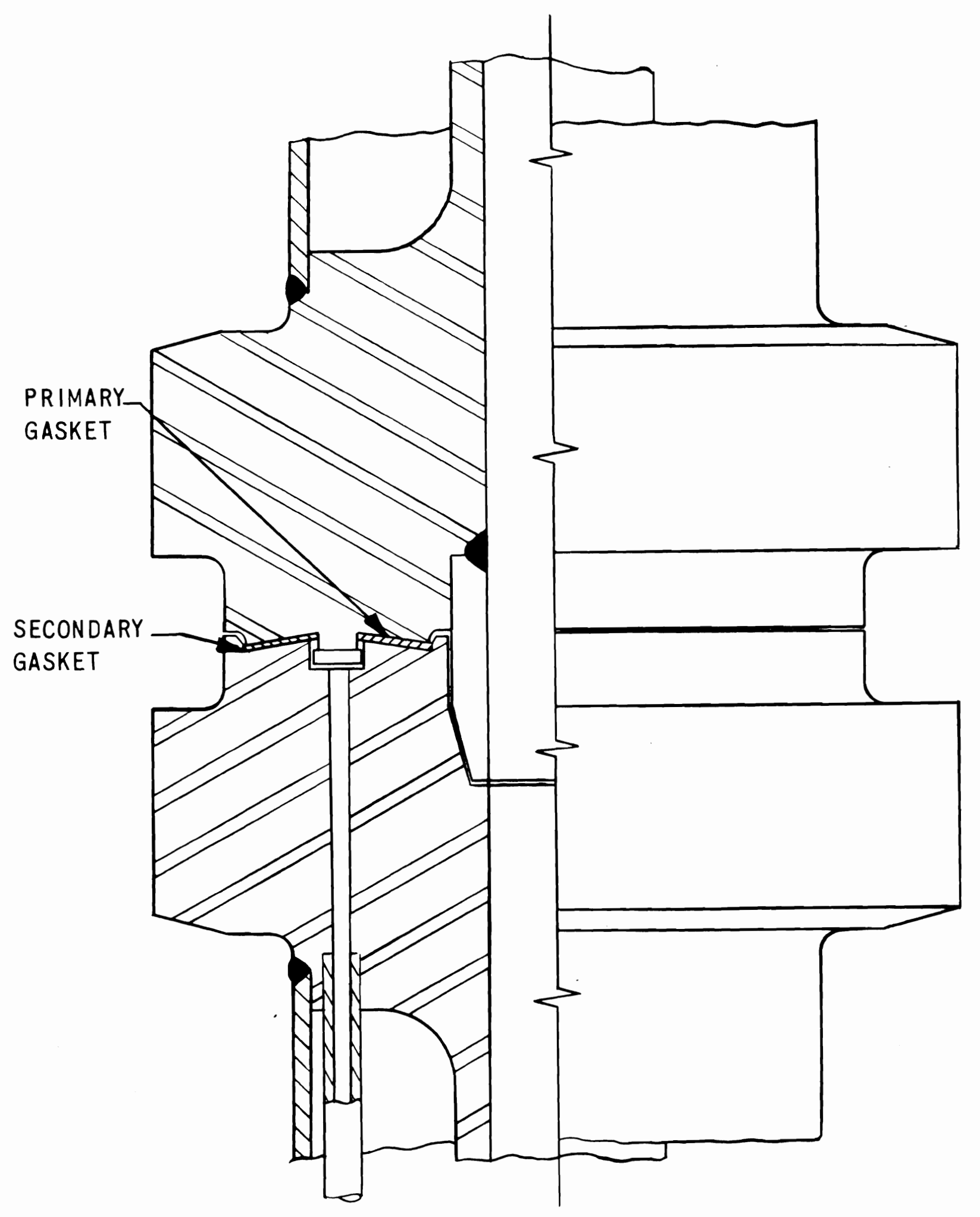

FIGURE 25. Double Conoseal Flange 


\section{Freeze Sea 1}

\section{-Description-}

A freeze seal design, shown in Figure 26, utilizes a solidified seal obtained by cooling the molten salt of the coolant system. This joint was designed and tested by Oak Ridge National Laboratory for the Molten-Salt Reactor. The molten salt used has a melting point greater than $600^{\circ} \mathrm{F}$.

The configuration consists of a flanged joint which has a frozen seal of molten salt to prevent leakage of the salt from the loop through the space between the flanges. An additional seal of soft iron or copper rings is provided to minimize gas leakage during shutdowns of the loop. Heat transfer from the molten salt of the loop to the outer edge of the flange is reduced by providing a narrow section in the flange. In addition, there are passages for air cooling in each flange. The flange has a thin cross section between the flange hub and the seal ring near the outer edge of the flange. The purpose of this is to have a small cross-sectional area for radial heat conduction. Four webs add strength to the flange and reduce the possibilities of warping. The flanges are made of Inconel. The three seal rings tested were made of stainless steel, soft iron, and annealed copper.

The freeze flange is forced together and retained by two hollow disc halves. The outside surface of the flange is tapered to allow wedging by the disc halves. Methods were developed for remotely engaging and disengaging the flange ${ }^{18}$.

\section{-Evaluation-}

Results of the tests utilizing the copper ring indicated that the flanges allowed no salt leakage, and gas leakage rates were satisfactory when cycled between room temperature and $1300^{\circ} \mathrm{F}$. There was no indication of any cracks due to thermal stresses. 
Aithough the flange was used in a remote handling application, there are several reasons why this design does not appear attractive for FFTF application. The first problem would be the increased thermal stresses resulting from the much lower melting point of sodium. The second problem is the inherently large size of this joint design that is required to achieve a temperature drop that permits coolant solidification.

-Recommendation-

Because of the reasons mentioned above, it is recommended that the Freeze Seal not be used as a candidate for the FTR top face open test position and closed loop static mechanical sealing mechanism. 


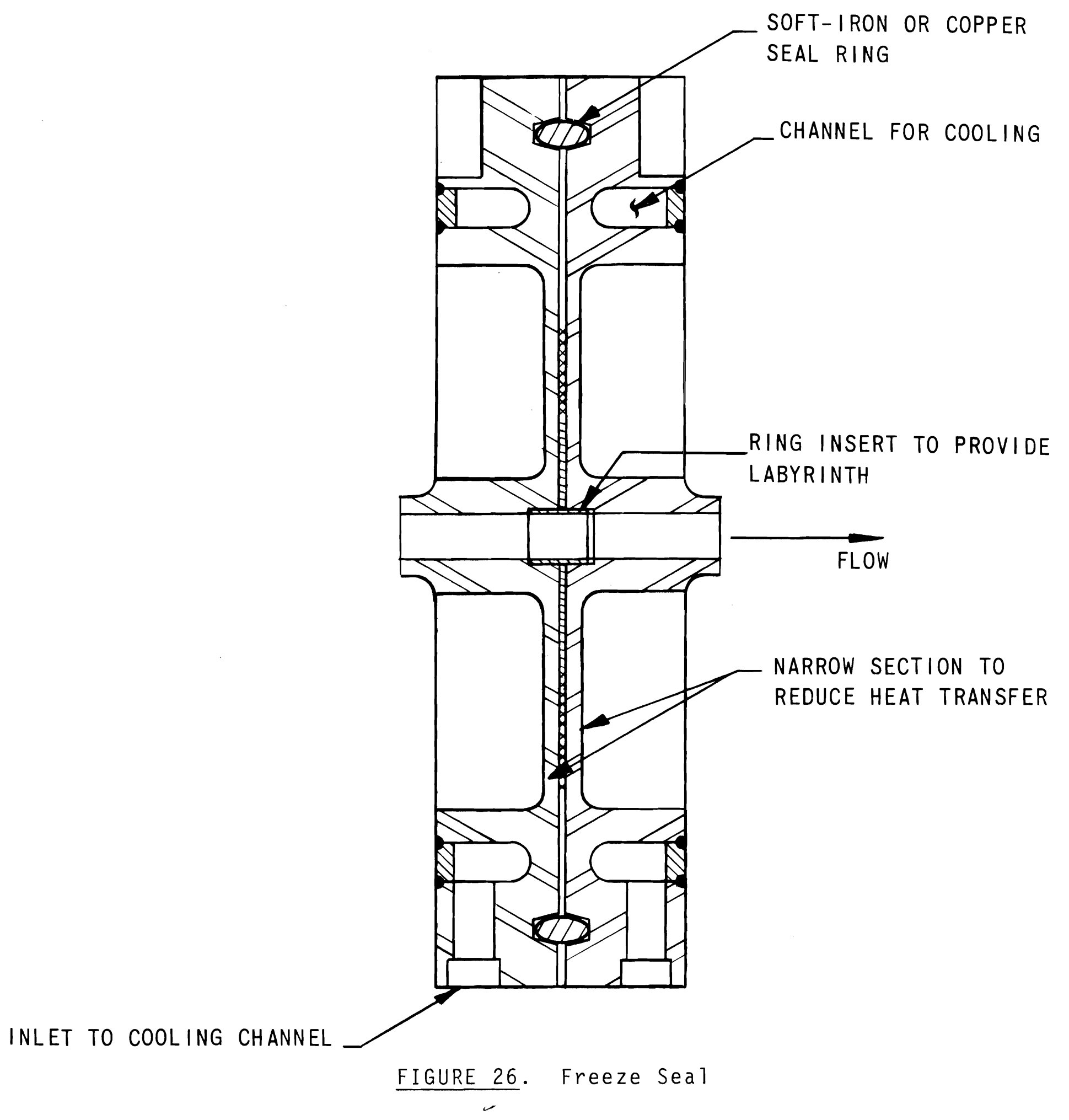




\section{Fused Seal}

\section{-Description-}

A fused seal design (Figure 27), designed and tested by ORNL ${ }^{15}$, utilizes plastic deformation which results from application of high temperature ${ }^{15}$. The seal was specifically designed for high temperature liquid metal service.

The configuration consists of a flanged joint which has a cast metal seal between the two halves. Various sealing materials were tested. A cast silver seal was used on one test and an alloy of $72 \%$ silver and $28 \%$ copper was used, on the other test. A seal is formed by fusion of the sealing material before the loop is charged with coolant. The seal material is in the solid state during operation. The sealing surfaces on the flange faces are flash copper plated, and then nickel plated, to promote good wetting by the sealing al10y.

\section{-Evaluation-}

Results of the testing indicated no molten salt leakage during any of the testing ${ }^{16}$. There was no indication of gas leakage using a leak detection fluid on the flanges. However, disassembly of the flanges revealed a proble:n area: there was self-welding between nuts and bolts and between flanges and the cast seal ring. Since all of the disassembly operations for the FTR will be accomplished remotely, it is clear that the cast seal joints, as tested, would not be satisfactory in this respect.

After reassembly, it was found that the joint leaked helium badly at the interfaces of the flange halves when subjected to operatina pressure and ambient temperature.

\section{-Recommendation-}

Because of the inherent difficulties in operating this seal, it is recommended that the fused seal not be considered as a candidate for the FTR top face open test position and closed loop static mechanical sealing mechanism. 


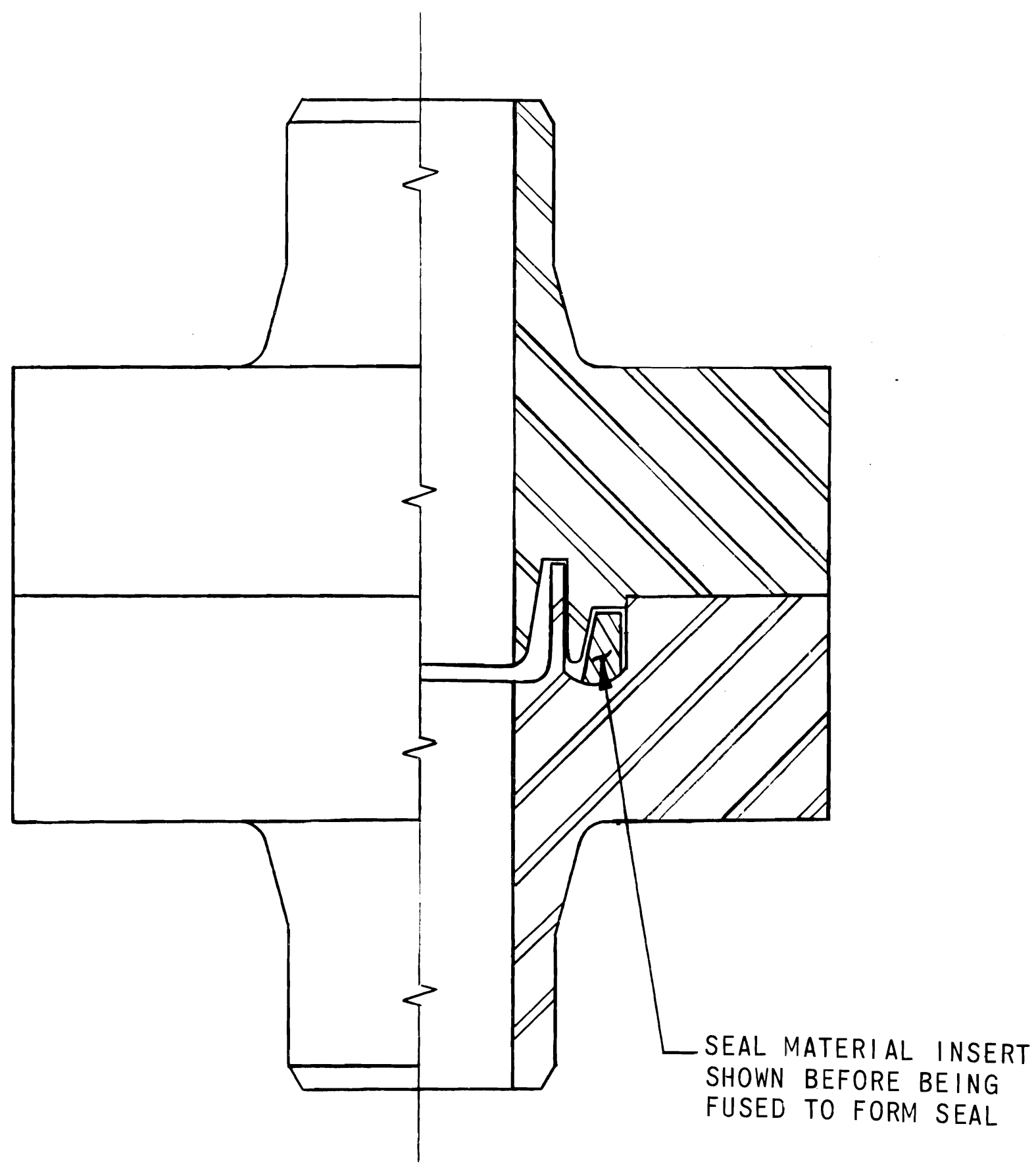

FIGURE 27. Fused Seal 
Swedish Sealing Device

-Description-

British Patent Specification No. 780, 151, as shown in Figure 28, was submitted by a Swedish firm on November 29, 1954. The seal is formed when a small chamber between the liquid metal and a soft metal rin? is filled with an inert gas. By using this design, it is possible to use proven gas seal technology to initiate a seal. The sealing device was designed specifically for liquid sodium coolant systems and remote operation adaptability.

\section{-Evaluation-}

There was no documented test data found on this design.

-Recommendation-

Because of the large space required for this sealing device, it is recommended that the Swedish sealing device not be considered as a candidate for the FTR top face open test position and closed loop static mechanical sealing mechanism. 


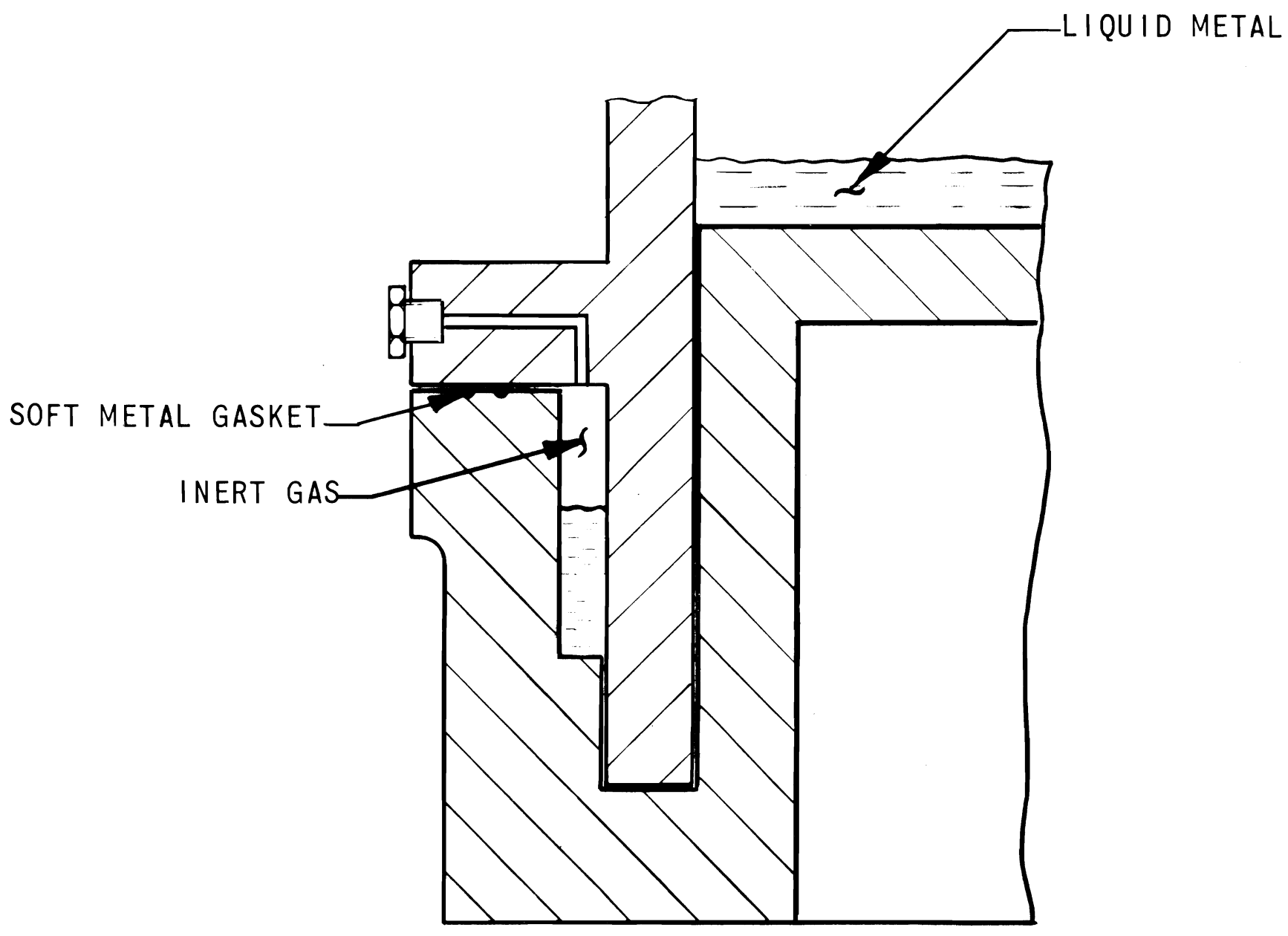

FIGURE 28. Swedish Joint 


\section{REFERENCES}

1. R. C. Walker, Unpublished Data, "FFTF Reference Concept Summary Description." Battelle-Northwest, Richland, Washington, January, 1969. (Preliminary Report.)

2. "Mass Transfer and Properties Changes Effects on Austenitic Steels in Flowing Sodium," E. L. Zebroski, R. S. Young, F. Z. Comprel1i, and D. Dutina, SM-85/28, IAEA 1966 Conference, Vienna, Austria.

3. "Static and Sliding Contact Behavior of Materials in Sodium Environments at Elevated Temperatures," W. J. Freede, L. Newcomb, and R. S. Kennedy, NAA-SR-12446, Contract AT(04-3)-700 Liquid Metal Engineering Center, September 29, 1967.

4. "FFTF Materials Design Data," R. A. Moen, BNWL-891, October 1968.

5. "Use of Flanged Joints in Liquid Metal Service," C. Clifford and G. Burnett, Chemical Engineering, September 18, 1961.

6. "Testing of Sodium Pipe Joints and Development of Remote Repair Tools for the SDR," H. Belofsky, S. Lazarus, and B. Minushkin, NDA-84-20, May 22, 1959.

7. "Tests of a Mechanical Pipe Joint for Sodium Service," C. Sutherland, NAA-SR-42-4, January 15, 1960.

8. "Dome Seal Performance Tests," D. H. White, HW-79205, November, 1963.

9. "Design Features of the Waste Solidification Engineering Prototypes," K. J. Schneider and V. P. Kel1y, CONF-66020, Waste Disposal and Processing, February 15, 1966.

10. "Design Development Tests of Some Components for the 10 MVe SDR," C. Bolta, B. Minushkin, H. Steinmetz, and 0. Sullivan, NDA-84-21, May 25, 1959.

11. "Holding High Pressure Joints," W. Coopey, Petrol Refiner, Mav, 1956, pp. 189-193.

12. "High-Temperature Bolted Flanged Joints," W. P. White and N.A.C. Bromidge, TRG-Report-1404(R), Paper 2, December 5, 1966.

13. "Interim Report-- Mechanical Joint Evaluation Program," J. E. Amos and R. E. MacPherson, ORNL-CF-60-9-77, September 26, 1960.

14. "Disconnect Testing Recommendations," L. E. Glasgow, AI-84, BNW Task 60-001-34, June 2, 1966. 


\section{$\mathrm{R}-2$}

15. "Molten-Salt Reactor Program Quarterly Proaress Report for Period Ending January 31, 1958," A. S. O1son, ORNL-2474, May 14, 1958.

16. "Screen Tests of Mechanical Pipe Joints for a Fused Salt Reactor System," W. B. McDonald, E. Storto, and A. S. O1son, ORNL-CF-58-8-33. August 13, 1958.

17. "High Integrity Bulk Packaging for Long-Term Storage of Radioactive Wastes," J. W. Kolb, RL-SA-60, February 9, 1966.

18. "Molten-Salt Reactor Experiment Semi-annual Progress Report for Period Ending July 31, 1964," ORNL-3708, Novernber, 1964. 


\section{BIBLIOGRAPHY}

1. "Fast Flux Test Facility Overal1 Conceptual System Design Description,"

C. C. Steele, BNWL-500, July 7, 1967.

2. Mass Transfer and Properties Changes Effects on Austenitic Steels in Flowing Sodium," E. L. Zebroski, R. S. Young, F. A. Comprelli, and D. Dutina, SM-85/28, IAEA 1966 Conference, Vienna, Austria.

3. "Static and Sliding Contact Behavior of Materials in Sodium Environments at Elevated Temperatures," W. J. Freede, L. Newcomb, and R. S. Kennedy, NAA-SR-12446, Contract AT(04-3)-700 Liquid Metal Engineering Center, September 29, 1967.

4. "Use of Flanged Joints in Liquid-Metal Service," C. Clifford and G. Burnett, Chemical Engineering, September 18, 1961.

5. "Testing of Sodium Pipe Joints and Development of Remote Repair Tools for the SDR," H. Belofsy, S. Lazarus, and B. Minushkin, NDA-84-20, May 22, 1959.

6. "Components of the Fused-Salt and Sodium Circuits of the Aircraft Reactor Experiment," H. W. Savage, W. B. McDonald, G. D. Whitman, and W. G. Cobb, ORNL-2348, September 18, 1958.

7. "The Development of Pumps for Ise in Fast-Reactor-Safety Intearal Loop Experiments," L. E. Robinson and R. D. Carlson, ANL-7369, Apri1, 1968.

8. "High-Temperature Bolted Flanged Joints," W. P. White and N.A.C. Bromidge, TRG-Report-1404(R). Paper 2, December 5, 1966.

9. "Design Features of the Waste Solidification Engineering Prototypes:" 6. J. Schneider and V. P. Kelly, CONF-66020, Waste Disposal and Processing, February $15,1956$.

10. "Design Development Tests of Some Components for the 10 MVe SDR," C. Bolta, B. Minushkin, H. Steinmetz, and 0. Sul1ivan, NDA-84-21, May 25, 1959.

11. "Interim Report-- Mechanical Joint Evaluation Program," J. E. Amos and R. E. MacPherson, ORNL-CF-60-9-77, September 26, 1960.

12. "Tests of a Mechanical Pipe Joint for Sodium Service," C. Sutherland, NAA-SR-4204, January 15, 1960.

13. "Molten-Salt Reactor Program Quarterly Progress Report for Period Ending January 31, 1958," A. S. 01son, ORNL-2474, May 14, 1958.

14. "Screen Tests of Mechanical Pipe Joints for a Fused Salt Reactor System," W. B. McDonald, E. Storto, and A. S. 01son, ORNL-CF-58-8-33, August 13, 1958. 
15. "Molten-Sa1t Reactor Experiment Semi-annual Progress Report for Period Ending July 31, 1964, ORNL-3708, November 1964.

16. "Holding High Pressure Joints," W. Coopey, Petrol, Refiner, May 1956, pp. 189-193.

17. "Disconnect Testing Recommendations," L. E. Glasgow, AI-84, BNW Task 60-001034, June 2, 1966.

18. "High Integrity Bulk Packaging for Long Term Storage of Radioactive Wastes," J. W. Kolb, RL-SA-60, February 9, 1966.

19. "Aircraft Nuclear Propulsion Project Quarterly Progress Report for Period Ending March 10, 1956," Oak Ridge National Laboratory, 1956.

20. "Annual Technical Report, AEC Unclassified Programs, January-December 1957," Part 1, NAA-SR-2400, Atomics International Div., North American Aviation, Inc., Canoga Park, California.

21. "Molten-Salt Reactor Program Quarterly Progress Report for Period Ending January 31, 1959," ORNL-2684, Oak Ridge National Laboratory, Tennessee.

22. "Molten-Salt Reactor Program Quarterly Progress Report for Period Ending October 31, 1958," ORNL-2626, Oak Ridge National Laboratory, Tennessee.

23. "Technology of Liquid Metals," W. H. Savage, ORNL-TR-854, Apri1, 1965.

24. "Aircraft Nuclear Propulsion Project Quarterly Progress Report for the Period Ending December 31, 1957," ORNL-2400 DEL, Oak Ridge National Laboratory, Tennessee.

25. "Reactor Engineering Division Quarterly Report [for] December 1, 1953 Through March 20, 1954," ANL-5260 (DEL 2) Argonne National Laboratory, Lemont, Illinois.

26. "Sodium Graphite Reactor Quarterly Progress Report [for] December 1953 February 1954," G. M. Inman, NAA-SR-1027, Atomics International Division, North American Aviation, Inc., Canoga Park, California.

27. "Reactor Engineering Division Quarterly Report--Section 11 [for] July, August, September 1956," ANL-5657, Argonne National Laboratory, Lemont, Illinois.

28. "The Compatibility of Kerosene with Sodium in a Closed System to $1200^{\circ} \mathrm{F}$," G. M. Wolten and R. A. Meyer, NAA-SR-5687, Atomics International Division, North American Aviation, Inc., Canoga Park, California.

29. "Aircraft Nuclear Propulsion Quarterly Progress Report for Period Ending December 10, 1955," ORNL-2012 (Pts. 1-2-3) (DEL), Oak Ridge National Laboratory, Tennessee, 1959.

30. "Reactor Engineering Division Quarterly Report [for] Apri1 1, 1955 Through June 30, 1955," ANL-5471, Argonne National Laboratory, Lemont, I11inois. 
31. "Aricraft Nuclear Propulsion Project Quarterly Progress Report for Period Ending March 10, 1953," ORNL-1515, Oak Ridge National Laboratory, Tennessee, Apri1 15, 1953.

32. "Aircraft Nuclear Propulsion Project Quarterly Progress Report for Period Ending June 10, 1956," ORNL-2106 (Pts, 1-5) (DEL), Oak Ridge National Laboratory, Tennessee, 1956.

33. "Reactor Engineering Division Quarterly Report [for] October 1, 1954 Through December 31, 1954," ANL-5371, Argonne Nationa1 Laboratory, Lemont, I1linois, 1955.

34. "Trends in Sodium Equipment," R. W. Dickinson and J. B. Williams NUCL-19-65-61, January 1961.

35. "Piping Flexibility Analysis of Cavity Piping," C. P. Hughes and C. P. Craig, NAA-SR-MEMO-3436, January 20, 1959.

36. "Gas Ingestion and Sealing Capacity of Helical Groove Fluid Film Seal (Viscoseal) Using Sodium and Water as Sealed Fluids," L. P. Ludwig, T. N. Strom, and G. P. Allen, NASA-TN-D-3348, December 7, 1965.

37. "Annual Technical Progress Report AEC Unclassified Programs Fiscal Year 1959," Atomics International, Division of North American Avaiation, NAA-SR-3850, August 1, 1959.

38. "Proceeding of 1962 High-Temperature Liquid-Metal Heat Transfer Technology Meeting," Brookhaven National Laboratory, BNL-756, May 18, 1962.

39. "Liquid Metals Technology Abstract Bulletin," MSA Research Corporation, LM/TAB-21, February, 1963.

40. "Materials for Components in Fluoride and NaK Flow Systems," S. J. Basham, R. W. Endebrock, J. G. Stang, and E. M. Simons, BMI-1178, September 22, 1966.

41. "Metal-to-Metal and Metal-Gasketed Seals," F. 0. Rathbun, Jr. SAE Paper No. 650312, May 1965. 
$-$

APPENDIX A

Sketches

SK-3-14540

SK-3-14567

SK-3-12389

SK-3-14608 


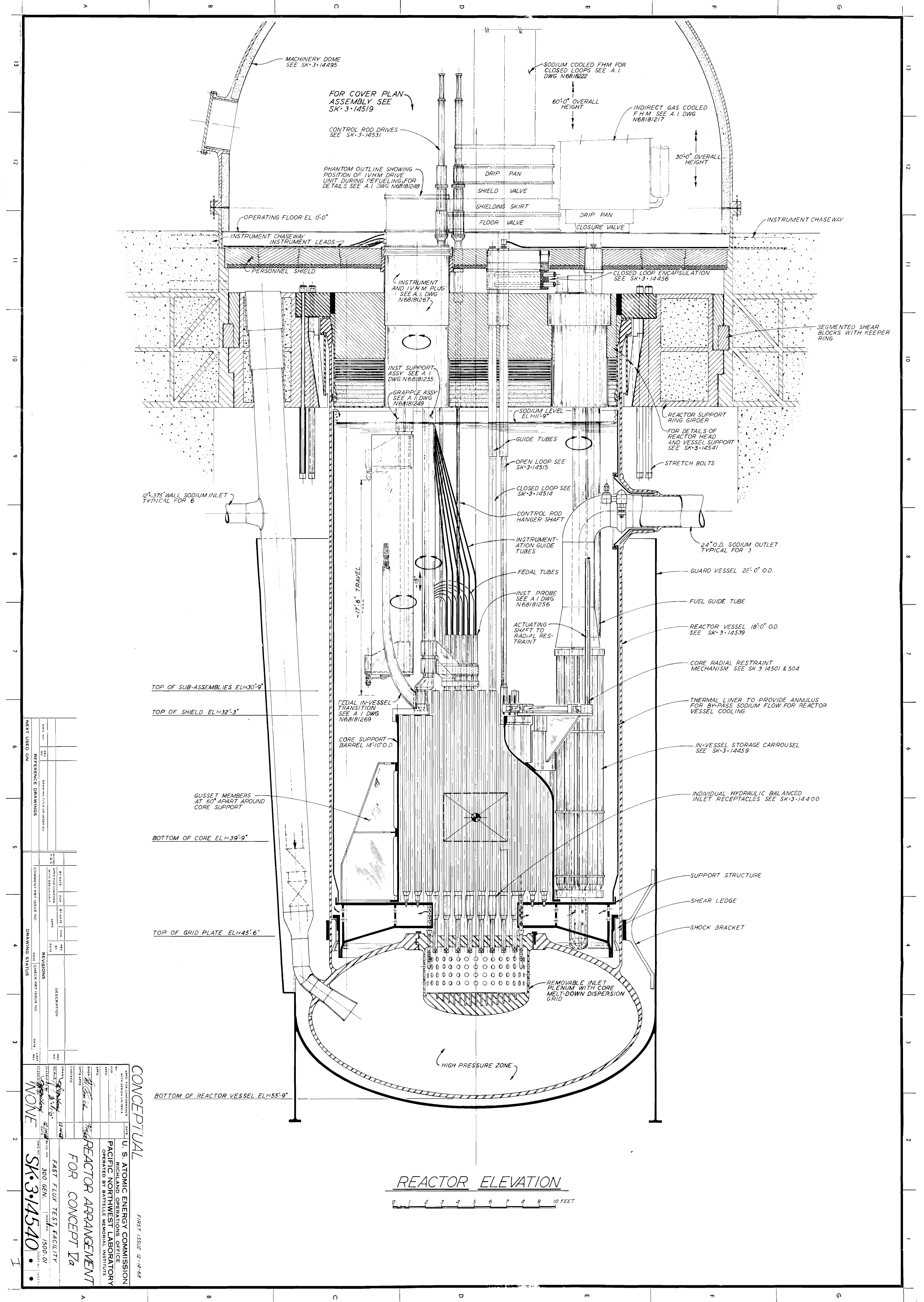




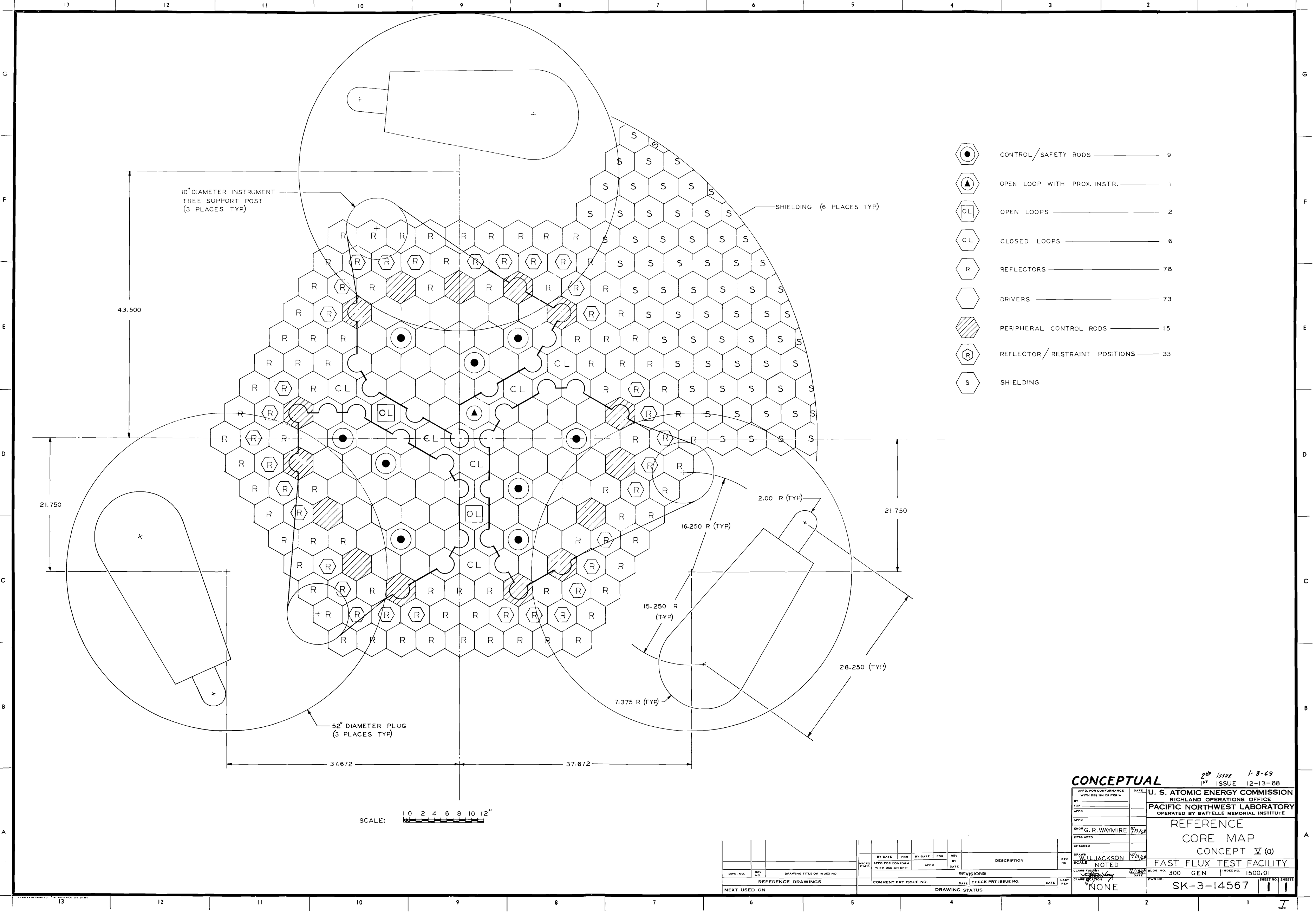




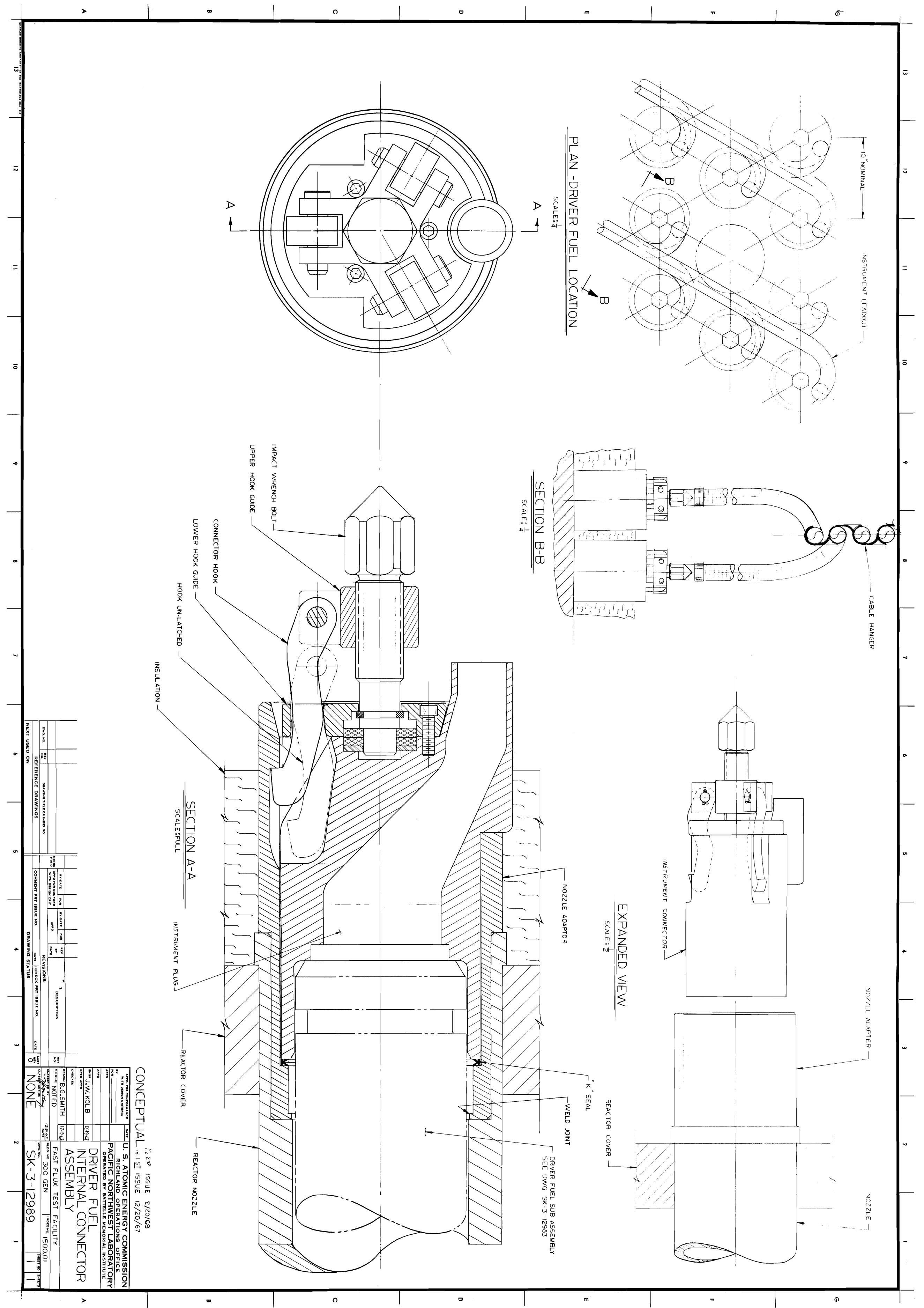




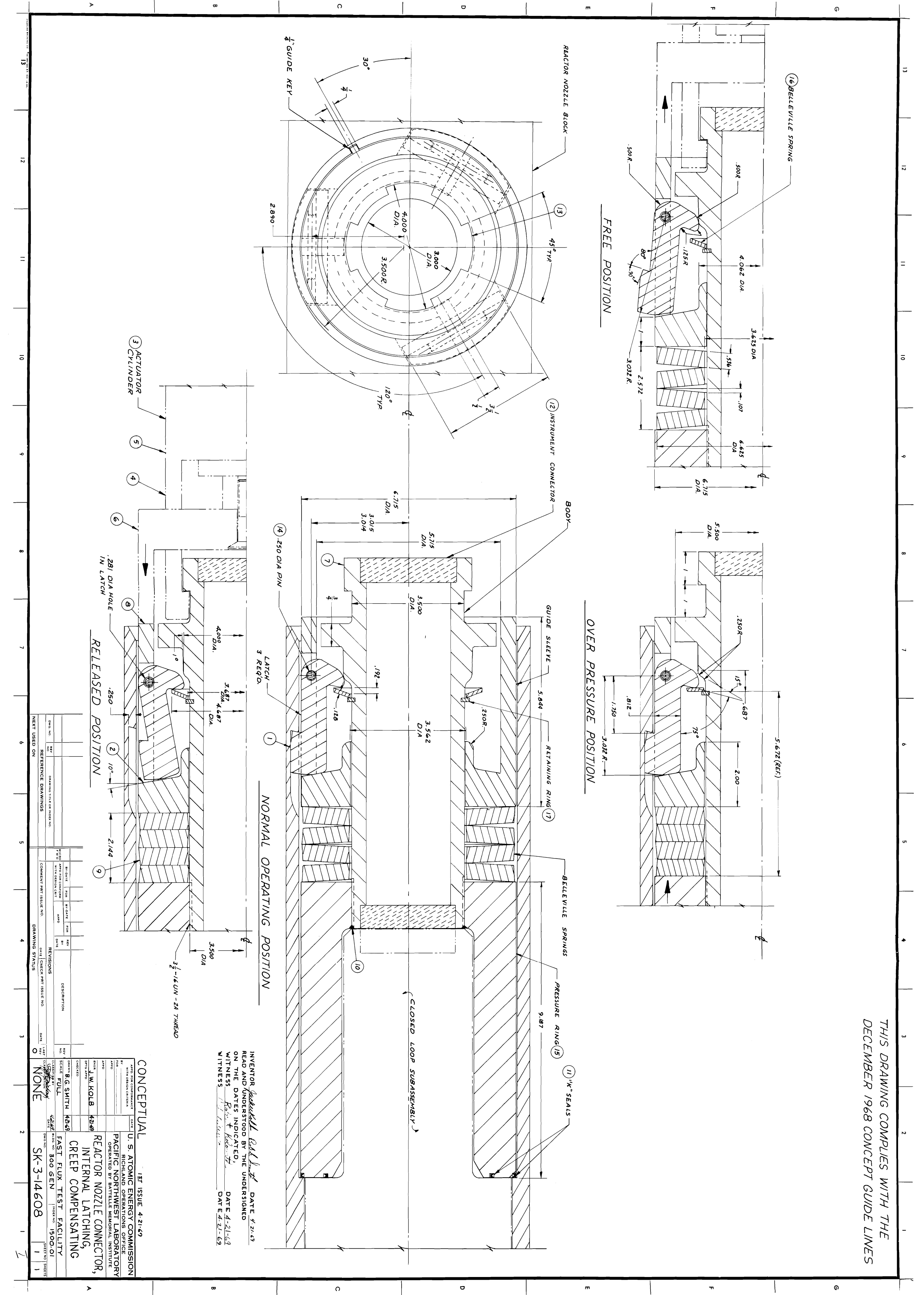




\section{DISTRIBUTION}

$\underline{\text { OFFSI TE }}$

AEC Chicago Patent Group

31 AEC Division of Reactor Development and Technology M. Shaw, Director, RDT

Asst Dir for Nuclear Safety

Analysis \& Evaluation Br, RDT:NS

Environmental \& Sanitary. Engr Br, RDT:NS

Research \& Development Br, RDT:NS

Asst Dir for Plant Engrg, RDT

Facilities Br, RDT:PE

Components $\mathrm{Br}$, RDT:PE

Instrumentation \& Control Br, RDT:PE

Liquid Metal Systems Br, RDT:PE

Asst Dir for Program Analysis, RDT

Asst Dir for Project Mgmt, RDT

Liquid Metals Projects Br, RDT:PM

FFTF Project Manager, RDT:PM (3)

Asst Dir for Reactor Engrg, RDT

Control Mechanisms $\mathrm{Br}$, RDT:RE

Core Design Br, RDT:RE (2)

Fuel Engineeririg $\mathrm{Br}, \mathrm{RDT}: \mathrm{RE}$

Fue 1 Handling $\mathrm{Br}$, RDT : RE

Reactor Vessels Br, RDT:RE

Asst Dir for Reactor Tech, RDT

Coolant Chemistry Br, RDT:RT

Fuel Recycle Br, RDT:RT

Fue 1s \& Materials Br, RDT:RT

Reactor Physics Br, RDT:RE

Special Technology Br, RDT:RT

Asst Dir for Engrg Standards, RDT

EBR-II Project Manager, RDT:PM

1 AEC Idaho Operations Office

Nuclear Technology Division

C. W. Bills, Director

1 AEC San Francisco Operations Office Director, Reactor Division

$4 \quad$ AEC Site Representatives

Argonne National Laboratory

Atomics International

Atomic Power Development Assoc.

General Electric Co.

214 AEC Division of Technical Information Extension 
No. of

Copies

3 Argonne National Laboratory

R. A. Jaross

LMFBR Program Office

N. J. Swanson

1. Atomic Power Development Association

Document Librarian

8 Atomics International

FFTF Program office

E. Weisner (1)

Liquid Metal Information Center J. J. Droher (2)

2 Babcock \& Wilcox Co.

Atomic Energy Division

S. H. Esleeck

G. B. Garton

1 BNW Representative

N. A. Hill (ZPR I I )

1 Combustion Engineering

1000 MWe Follow-On Study

W. P. Staker, Project Manager

5 General Electric Company

Advanced Products Operation

Karl Cohen (4)

Nuclear Systems Programs

D. H. Ahmann

2 Gulf General Atomic Inc. General Atomic Div

D. Coburn

1 Idaho Nuclear Corporation

D. R. DeBoisblanc

1 Oak Ridge National Laboratory

W. O. Harms

1 Stanford University

Nuclear Division

Division of Mechanical Engineering

R. Sher

1 United Nuclear Corporation

Research and Engineering Center

R. F. DeAngelis 
No. of

Copies

10

Bechte1 Corporation*

J. J. Teachnor, Project Administrator, FFTF

18 Westinghouse Electric Corporation*

Atomic Power Division

Advanced Reactor Systems

N. J. Georges

W. E. Gunson

J . Haughton

D. C. Spencer

(15)

ONS ITE - HANFORD

1 Bechtel Corporation*

M. O. Rothwe11 (Richland)

1 Westinghouse Electric Corporation*

R. Strzelecki (Richland)

4 AEC RDT Site Representative

P. G. Holsted (3)

T. A. Nemzek

3 AEC Richland Operations Office

C. L. Robinson (2)

J. M. Shivley (1)

1 AEC Chicago Patent Group

R. K. Sharp (Richland)

3 Battelle Memorial Institute

125 Battelle-Northwest

S. 0. Arneson

E. R. Astley

R. G. Baumgarte 1

A. L. Bement

R. A. Bennett

J. D. Berg

L. R. Besel

C. L. Boyd

D. C. Boyd

C. M. Cantre11

J. R. Carre11

T. T. Claudson

J. C. Cochran

P. D. Cohn

D. L. Condotta

R. R. Cone

J. H. Cox

* Distribution by FFTF 
K. O. Creek

J. M. Davidson

V. A. Deliso

J. E. Erben

E. A. Evans

L. M. Finch

E. E. Garrett

S. M. Gil1

F. C. Gronemeyer

R. A. Harvey

K. D. Hayden

B. R. Hayward

J. W. Helm

L. G. Henke

R. J. Hennig

R. G. Hoagland (10)

P. L. Hofmann

$\mathrm{J}$. E. Irvin

M. T. Jakub

B. M. Johnson

H. G. Johnson

R. N. Johnson

E. M. Johnston

M. D. Jones

F. J. Kempf

W. C. Kinse 1

R. L. Knecht

J. W. Kolb

R. Kolowith (10)

D. Koreis

M. R. Kreiter

C. D. Leach

H. E. Little

C. E. Love

M. K. Mahaffey

W. B. McDonald

J. S. McMahon

R. A. Moen

C. A. Munro

C. R. Nash

J. C. Noakes

R. E. Peterson

H. L. Pringle

M. O. Rankin

D. E. Rasmussen

R. L. Roske

E. J. Ruane

F. H. Shadel 
No. of

Copies

D. W. Shannon (2)

P. Shaw

D. E. Simpson

C. R. F. Smith

R. J. Squires

J. M. Steichen

D. D. Stepnewski

G. H. Strong

C. D. Swanson

J. C. Tobin

K. G. Toyoda

J. C. Tverberg

M. A. Voge 1

R. C. Wa1ker

J. H. Westsik

T. W. Withers

N. G. Wittenbrock

M. R. Wood

R. R. Wyer

Lega1 - 703 B $1 \mathrm{dg}$.

Lega1 - ROB, 221-A

BNW - Technical Information (5)

BNW - Technical Publications (2)

FFTF File (703) (10)

FFTF TPO (703) (3) [List "T"] 